\title{
Characterisation of the symbionts in the Mediterranean fruitfly gut
}

2
Darrington, M. ${ }^{1 *}$, Leftwich, P.T. ${ }^{1 *}$, Holmes, N.A. ${ }^{1,4}$, Friend, L.A. ${ }^{1}$, Clarke N.V.E. ${ }^{1}$, Worsley, S.F. ${ }^{1}$, Margaritopolous, J.T. ${ }^{2}$, Hogenhout, S.A. ${ }^{3}$, Hutchings, M.I. ${ }^{1,4}$ \& Chapman, $\mathrm{T}^{\wedge 1}$

${ }^{1}$ School of Biological Sciences, University of East Anglia, Norwich Research Park, Norwich, NR4 7TJ, UK.

${ }^{2}$ Department of Plant Protection, Institute of Industrial and Fodder Crops, Hellenic Agricultural Organization-DEMETER, Volos, Greece

${ }^{3}$ Department of Crop Genetics, John Innes Centre, Norwich Research Park, NR4 7UH, Norwich, UK

${ }^{4}$ Department of Molecular Microbiology, John Innes Centre, Norwich Research Park, Norwich, NR4 $7 \mathrm{UH}, \mathrm{UK}$.

*Joint first authors

ORCID: PTL 0000-0001-9500-6592

ORCID: TC 0000-0002-2401-8120

ORCID: NAH 0000-0002-4979-9680

ORCID: SFW 0000-0003-4736-0938

ORCID: SAH 0000-0003-1371-5606

ORCID: MH 0000-0001-6628-5940

ORCID: JM 0000-0002-5893-8400

^Correspondence: tracey.chapman@uea.ac.uk

Running head: medfly gut microbiome

Keywords: Klebsiella oxytoca, symbiont, paratransgenesis, 16S rDNA sequencing. 


\section{Abstract}

32 Symbioses between bacteria and their insect hosts can range from very loose associations through to obligate interdependence. While fundamental evolutionary insights have been gained from the indepth study of obligate mutualisms, there is increasing interest in the evolutionary potential of flexible symbiotic associations between hosts and their gut microbiomes. Understanding relationships between microbes and hosts also offers the potential for exploitation for insect control. Here, we investigate the gut microbiome of a global agricultural pest, the Mediterranean fruitfly (Ceratitis capitata). We used $16 \mathrm{~S}$ rRNA profiling to compare the gut microbiomes of laboratory and wild strains raised on different diets and from flies collected from various natural plant hosts. The results showed that medfly guts harbour a fairly simple microbiome, primarily determined by the larval diet in both wild and laboratory flies. However, regardless of the laboratory diet or natural plant host on which flies were raised, Klebsiella spp dominated the medfly microbiomes and resisted removal by antibiotic treatment. We sequenced the genome of the dominant putative Klebsiella spp (designated 'Medkleb') isolated from the gut of the Toliman wild type fruitfly strain. Genome-wide ANI analysis placed Medkleb within the K. oxytoca / michiganensis group. Molecular, sequence and phenotypic analyses supported its identity as $K$. oxytoca. Medkleb has a genome size (5 825435 bp) which is 1.6 standard deviations smaller than the mean genome size of free-living Klebsiella spp, and lacks some genes involved in environmental sensing. Moreover, the Medkleb genome contains at least two recently acquired unique genomic islands as well as genes that encode pectinolytic enzymes capable of degrading plant cell walls. This may be advantageous given that the medfly diet includes unripe fruits containing high proportions of pectin. These results suggest that the medfly harbours a commensal gut bacterium that may have developed a mutualistic association with its host and provide nutritional benefits. 


\section{Introduction}

All eukaryotic organisms host bacteria (McFall-Ngai et al 2013) and some of the best-studied associations are those that occur between insects and bacteria (Moran et al 2008; McCutcheon and Moran 2011; Moran and Bennett 2014). The majority of microbe-insect interactions are temporary associations. However, some bacteria and insects retain persistent associations over evolutionary time and have evolved co-dependence (Moran et al 2008). In the most extreme examples, these associations have persisted for millions of years and represent intimate co-evolutionary relationships (Moran et al 2005; Moran et al 2008).

Heritable symbioses are one such example and are defined by the direct passage of bacteria from insects to progeny, usually via maternal transmission (Moran et al 2008). These symbioses can be facultative or obligate (Moran et al 2008). Over evolutionary time, facultative symbionts may lose genes that facilitate life in varied environments (Moran and Bennett 2014). A transition to evolutionary interdependence with hosts can often be identified by reduced genome size and reduced GC content (Shigenobu et al 2000; van Ham et al 2003; Wu et al 2006; Hansen et al 2011; Bennett and Moran 2013; Husnik et al 2013). Novel loci can also be acquired via lateral gene transfer or loci deleted through genome reduction (Ochman et al 2000; Ochman and Davalos 2006). Mutualistic benefits provided to insects by bacteria include synthesis of nutrients (Sabree et al 2013; Storelli et al 2018; Sinotte et al 2018), carotenoids (Sloan and Moran 2012), and antipredation molecules (Oliver et al 2003; Sinotte et al 2018). Heritable symbionts include "reproductive parasites" that enhance their fitness by distorting the sex ratios of the hosts' offspring (Hurst and Frost 2015). For example, male Zyginidia pullulan leafhopper embryos are feminised by maternally-inherited Wolbachia bacteria (Negri et al 2009). Feminisation benefits Wolbachia, because these bacteria preferentially reside within ovaries and therefore are transmitted across generations at higher frequency (Negri et al 2009). The Buchnera symbionts of aphids have been extensively studied and represent an example of an advanced obligate mutualism (Shigenobu et al 2000; Tamas et al 2002; van Ham et al 2003). Buchnera spp have been associated with aphids for approximately 100M years (Von Dohlen and Moran 2000) and provide the host with essential amino acids (Shigenobu et al 2000). There is an increasing body of research into the identities and potential roles of diverse symbionts found across many different taxa (de Souza et al 2009; Weiss and Kaltenpoth 2016; Holmes et al 2016; Whitten and Dyson 2017; Ballinger and Perlman 2017; Anbutsu et al 2017; Heine et al 2018) including those that are only loosely associated with their hosts, such as the gut symbionts of fruitflies that are the focus of this study.

There are many examples of studies in which the culturable and non-culturable members of gut microbiome communities have been characterised via sequencing of specific regions of the bacterial 16S rDNA. These works show that dipteran gut microbiomes are often relatively stable and simple (Chandler et al 2011; Gould et al 2018; Deguenon et al 2019) and can in some species 
be strongly influenced by host diet (Chandler et al 2011; Woruba et al 2019). For example, the gut microbiome of Drosophila melanogaster is consistently formed by a core of five species: Lactobacillus plantarum, Lactobacillus brevis, Acetobacter pasteurianus, Acetobacter tropicalis and Acetobacter orientalis (Gould et al 2018). These simple microbiomes appear to contain bacteria that reliably colonise the gut, suggesting the potential for hosts to actively regulate their gut microbiomes (Lhocine et al 2008; Bosco-Drayon et al 2012; Lindberg et al 2018) and gain potential benefits from doing so (Gould et al 2018). The five core members of the $D$. melanogaster gut microbiome metabolise lactic acid and acetic acid, which may benefit larvae feeding on rotten fruit. In contrast, the Tephritidae family of "true fruit-fly" pests hatch in unripe fruit and the culturable species within their gut microbiomes are reported to contain pectinolytic bacteria, which could assist the host in breaking down plant cell walls (Behar et al 2008b; Ben-Yosef et al 2014; Liu et al 2016).

Manipulation of the co-evolved intimacy of symbionts and hosts via paratransgenesis has the potential to be used as a novel mode of pest insect control (Durvasula et al 1997; Whitten et al 2016). Gut symbionts have the potential to augment strategies for control as probiotics. For example, they could boost fitness in insects such as Mediterranean fruitflies (medfly, Ceratitis capitata) that are subjected to potentially damaging irradiation as part of sterile insect release control programmes (Jurkevitch 2011). The potential utility of symbionts to either provide new routes for pest control or to improve existing technologies (Leftwich et al 2016) has led to increasing interest in investigating the symbiotic gut microbial communities of key global pests, such as the medfly (Behar et al 2008a; Behar et al 2008b; Ben Ami et al 2010; Gavriel et al 2011), which is the focus of investigation here.

Investigations of culturable gut bacteria in medfly have been predominantly performed using amplified rDNA restriction analysis (ARDRA). These show that Klebsiella spp comprise at least 20$30 \%$ of the larval, pupal and adult medfly gut microbiomes (Behar et al 2008b; Ben Ami et al 2010; Aharon et al 2013). This has led to the hypothesis that $K$. oxytoca might benefit larval nutrition via its reported pectinolytic activity against fruit sugars, or due to its ability to fix nitrogen (Behar et al 2008b). 16S rDNA analysis has also been used to show that irradiation can alter the microbiome, and particularly diminishes the relative contribution of Klebsiella spp (Ben Ami et al 2010). Subsequent reintroduction of $K$. oxytoca to irradiated flies significantly reduced mating latency in comparison to males fed sterile diet (Ben Ami et al 2010), suggesting a potential host fitness benefit.

Although the culturable species within medfly microbiomes have been described, with Klebsiella spp appearing to be a typical component, many details remain unknown. For example, we do not yet know the contribution of non-culturable species to both laboratory and wild medfly, whether microbiomes are stable, whether Klebsiella spp have the capability to confer a direct fitness benefit 
130 to the medfly, and the extent to which Klebsiella is heritable. Behar et al. (Behar et al 2008a) suggest

131 that a gut symbiont identified as $K$. oxytoca is heritable and can be transmitted during oviposition.

132 However, K. oxytoca was detected in only 1 of 4 replicate samples (Behar et al 2008a) and the

133 potential transmission of $K$. oxytoca during oviposition could not be ruled out . Recovery of GFP

134 labelled Klebsiella bacteria in the guts of offspring of mothers into which those bacteria were

135 experimentally introduced provides stronger evidence of vertical transmission (Lauzon et al 2009),

136 though the relative importance of this mechanism is not yet clear. In terms of fitness benefits, Gavriel

137 et al. (Gavriel et al 2011) experimentally depleted the microbiome of male medflies by using

138 irradiation andfed males with a diet either containing $K$. oxytoca (pro) or a sterile diet (ster). pro

139 outcompeted ster flies for matings, and females mated to pro males were less inclined to re-mate.

140 These data suggest that Klebsiella spp could confer host benefits (Behar et al 2008b; Ben Ami et al

141 2010; Gavriel et al 2011), though it is not yet clear whether this occurs in the natural context.

143 Here we compared the culturable and non-culturable gut microbiomes of wild-collected adult

144 medflies from a range of different wild hosts, with those of the Toliman wild type laboratory strain

145 reared on a range of different larval diets in the presence and absence of antibiotics. We conducted

146 long-read genome sequencing and analysis of the genome of the dominant, putative $K$. oxytoca

147 (hereafter "Medkleb") spp extracted from the adult gut of Toliman wild type individuals. This was

148 done to confirm the phylogenetic placement of Medkleb and to interrogate the genome for features

149 characteristic of a nascent evolutionary interdependence with its medfly host. We assembled and

150 annotated the Medkleb genome sequence and tested for signatures of facultative transition, i.e. a

151 reduction in genome size or GC content (Moran et al 2008; McCutcheon and Moran 2011; Moran

152 and Bennett 2014). We conducted comparisons between Medkleb and other Klebsiella spp to reveal

153 phenotypes that might potentially facilitate a mutualistic relationship, or indicate restrictions to the

154 environments in which Medkleb might live. We investigated tests of phenotypic features by testing

155 whether Medkleb had the capacity to synthesise secondary metabolites, and by conducting direct

156 biochemical tests for pectinolytic activity.

\section{Materials and Methods}

159

\section{Toliman Wild type strain}

161 To directly test the effect of different dietary carbohydrates on the gut microbiome, we raised three

162 replicate samples each of individuals from the Toliman wild type strain on different larval diets. This

163 strain originated from Guatemala and has been reared in the laboratory since 1990. Our Toliman

164 colony has been maintained in non-overlapping generations in a controlled environment room

165 (humidity $50 \pm 5 \%$, temperature $25 \pm 0.5^{\circ} \mathrm{C}$ ) on a $12: 12$ light:dark cycle for over 30 generations

166 (Leftwich et al 2017). Under this regime, larvae are raised on a sugar-yeast-maize medium (1\% agar,

$1677.4 \%$ sugar, $6.7 \%$ maize, $4.75 \%$ yeast, $2.5 \%$ Nipagin (10\% in ethanol), $0.2 \%$ propionic acid) and 
168

169

170

171

172

173

174

175

176

177

178

179

180

181

182

183

184

185

186

187

188

189

190

191

192

193

194

195

196

197

198

199

200

201

202

adults are given ad libitum access to sucrose-yeast food; 3:1 w/w sugar/ yeast hydrolysate, and water.

\section{Generation of laboratory and wild-derived gut microbiome samples}

\section{(i) Effect of the larval diet on the adult microbiome in the Toliman wild type}

To generate the samples of wild type flies raised on different diets ( \pm antibiotics) for subsequent gut dissection and 16S rRNA amplicon sequencing of the gut microbiome, Toliman flies were cultured from eggs collected over a $24 \mathrm{~h}$ period placed in one of four larval diet treatments. Three of these diets provided varying carbohydrate levels and sources, while maintaining the same yeast ( protein) level: 1) Sucrose High Protein (SHP), 2) Glucose \& 3) Starch. The fourth diet had a sucrose carbohydrate base but only $60 \%$ of the yeast content: Sucrose Low Protein, SLP (Table S1). We included Propionic acid as a food preservative (Leftwich et al 2018). All diet manipulations were done in the presence and absence of antibiotics. For the antibiotic treatments, each larval diet contained a final concentration of $100 \mu \mathrm{g} / \mathrm{ml}$ kanamycin, $200 \mu \mathrm{g} / \mathrm{ml}$ ampicillin, $200 \mu \mathrm{g} / \mathrm{ml}$ streptomycin, $50 \mu \mathrm{g} / \mathrm{ml}$ chloramphenicol, $100 \mu \mathrm{g} / \mathrm{ml}$ apramycin, $100 \mu \mathrm{g} / \mathrm{ml}$ hygromycin and $200 \mu \mathrm{g} / \mathrm{ml}$ tetracycline. Approximately 500 eggs were placed on $100 \mathrm{~mL}$ of the appropriate diet in a glass bottle. When third instar larvae started to "jump" from the larval medium, the bottles were laid horizontally on sand and pupae allowed to emerge for seven days. Pupae were then sieved from the sand and held in $9 \mathrm{~mm}$ petri dishes until adult eclosion.

(ii) Effect of wild larval diets on the adult microbiome in wild flies under natural conditions

Wild flies were collected at adult eclosion from fallen argan fruit in Arzou, Ait Melloul, Morocco, in July 2014, from Apricots, Oranges and Grapefruits in Chania, Crete, July-September 2014 and from Peaches, Oranges and Tangerines in Ano Lechonia, Greece, July-September 2014. All samples were preserved in $96 \%$ ethanol and sent to the UK before gut dissection and DNA extraction for the $16 \mathrm{~S}$ rRNA amplicon sequencing described below.

\section{16S rRNA gene sequencing and bioinformatics analysis of the gut bacteria derived from} laboratory- and wild- and derived adult medflies.

We analysed the composition of the gut microbiomes in the dissected guts of the laboratory and wild-derived flies describe above, by using $16 \mathrm{~S}$ rRNA amplicon sequencing. Each of the three biological replicates was a pool of five adult flies (Supplementary Information). Batches of flies were surface sterilized for 30 seconds in $0.5 \%$ sodium hypochlorite (bleach) (Sigma-Aldrich, Cat. No.7681529) and washed for 30 seconds in sterile $1 \mathrm{M}$ PBS ( $\mathrm{pH} 7.4)$ three times before being homogenized. $100 \mu \mathrm{L}$ of the third washes were used to check the surface sterilisation efficiency. There was no microbial growth in any of these tests.

We used sterilised pestles to homogenise the surface-sterilised samples inside 2-mL microcentrifuge tubes, with three freeze/thaw cycles in liquid nitrogen. DNA was extracted using the DNeasy Blood 
and Tissue Kit (Qiagen) and quality checked using a NanoDrop (Thermoscientific Nanodrop 8000 Spectrophotometer). Approximately $100 \mathrm{ng}$ of DNA per sample was used as the template for PCR amplification with bacterial universal primers 515F (5'-GTG CCA GCM GCC GCG GTA A-3') and 806R (5'-GGA CTA CHV GGG TWT CTA AT-3) against the 16S rRNA gene. Amplicon sequencing was performed using paired-end 250 bp V2 chemistry (Illumina MiSeq platform, Earlham Institute provider).

Demultiplexed sequences were obtained using mothur v38.2 (Schloss et al 2009), following their standard MiSeq operating procedures. Sequence variants were assigned to operational taxonomic units (OTUs) at a $97 \%$ similarity threshold. Taxonomy assignment of OTUs using the Silva database (release 132). The minimum library sizes per sample were $\sim 17 \mathrm{~K}$ after passing quality control. All statistical analyses of amplicon data were conducted in R v3.6.2 (R Core Team 2019) using the phyloseq (McMurdie and Holmes 2013), vegan (Oksanen et al 2007) and tidyverse (Wickham 2017) packages. Sequences were rarefied to normalise library sizes. Alpha diversity was estimated using the Shannon species diversity index. We visualised differences in bacterial community structure among samples (beta diversity) using non-metric multidimensional scaling (NMDS) plots of BrayCurtis distances and performed multivariate analysis of variance (PERMANOVA) with 999 permutations on Unifrac distance matrices.

\section{Genome sequencing of the dominant gut microbiome Klebsiella spp symbiont (Medkleb)} from the Toliman wild type

We investigated the identity of the recurrent Klebsiella spp bacterial symbiont through isolation of culturable Klebsiella spp. colonies from the Toliman strain.

(i) Clonal isolation. Clonal isolates of Klebsiella spp obtained from individuals of the Toliman wild type strain were made by taking surface sterilized, homogenised samples from adults reared under the standard conditions described above and plating them onto Simmon's Citrate LB Agar (with bromothymol blue as a colour indicator). This is a substrate recommended for the isolation of Klebsiella oxytoca and K. pneumoniae (Simmons 1926). Culture plates were made from 15 biological replicates of medfly. Cultures were checked for morphological uniformity and their identity confirmed with PCR amplification with universal bacterial primers $28 \mathrm{~F}$ and $806 \mathrm{R}$. Thirteen of the 15 isolates had identical 16S rRNA gene sequences and were BLAST matched to $K$. oxytoca and our most abundant OTU from $16 \mathrm{~S}$ rRNA amplicon sequencing. Two isolates contained colonies which BLAST matched to Pantoea spp. We chose a single Klebsiella spp colony at random for genomic sequencing, as described below.

(ii) DNA preparation. The single clonal isolate selected for genome sequencing was streaked onto LB media (15g/L Agar; $5 \mathrm{~g} / \mathrm{L} \mathrm{NaCl} ; 5 \mathrm{~g} / \mathrm{L}$ yeast extract; $1.5 \mathrm{~g} / \mathrm{L}$ glucose; $10 \mathrm{~g} / \mathrm{L}$ tryptone) and incubated overnight at $25^{\circ} \mathrm{C}$, then transferred into a $1.5 \mathrm{ml}$ microcentrifuge tube containing $1 \mathrm{ml}$ of $10 \%$ glycerol. 
The sample was vortexed for 30 secs then centrifuged at 12000 RPM for $10 \mathrm{~min}$. Glycerol was then removed, and the pelleted bacteria re-suspended in $2 \mathrm{ml}$ of SET buffer $(65 \% \mathrm{v} / \mathrm{v}$ molecular grade $\mathrm{H}_{2} \mathrm{O}$ (ThermoFisher); $20 \%$ v/v Tris (pH8); $5 \%$ v/v 5M NaCl; $5 \%$ v/v 10\% SDS; $5 \%$ v/v 0.5M EDTA) before transfer to a $15 \mathrm{ml}$ falcon tube. $20 \mu \mathrm{g}$ of lysozyme (Sigma) and $0.4 \mu \mathrm{g}$ achromopeptidase (Sigma) suspended in $40 \mu \mathrm{l}$ of molecular grade water (ThermoFisher) and $0.02 \mu \mathrm{g}$ of RNase (Fermentas) were added. The sample was mixed gently then incubated at $37^{\circ} \mathrm{C}$ for $2 \mathrm{hrs} .240 \mu \mathrm{L}$ of $10 \%$ sodium dodecyl sulphate and $56 \mu \mathrm{L}$ of proteinase $\mathrm{K}(20 \mathrm{mg} / \mathrm{ml})$ were added, before a second incubation at $56^{\circ} \mathrm{C}$ for $2 \mathrm{hrs}$, with manual mixing every 30 mins. $800 \mu \mathrm{L}$ of $5 \mathrm{M} \mathrm{NaCl}$ and $2 \mathrm{ml}$ of chloroform were added and the sample was mixed by hand for 10 mins, before centrifugation at 4000 RPM for 12 mins. The aqueous phase was then carefully transferred to a fresh tube. DNA was precipitated in 0.6 volume isopropanol, then transferred to a $1.5 \mathrm{ml}$ microfuge tube by pipette. DNA was washed once with $70 \%$ ethanol. Ethanol was removed, then $1 \mathrm{ml}$ of $70 \%$ ethanol was added, and DNA was left to incubate overnight at $4^{\circ} \mathrm{C}$. Ethanol was again removed, and DNA was resuspended in $200 \mu \mathrm{L}$ of molecular grade water (ThermoFisher).

(iii) Single molecule real time (SMRT/PacBio) Medkleb genome sequencing. DNA purity, concentration, and average fragment size were analysed using Nanodrop (ThermoFisher), Qubit v2.0 (Invitrogen) and Agilent Tapestation 4200 (Agilent) respectively. DNA was fragmented using a G-tube (Covaris), and SMRTbell library construction was carried out using a Template Prep Kit 1.0 (PacBio). The library was then size selected to $>7 \mathrm{~kb}$ using the BluePippin system (Sage Science). Sequencing was carried out on a Pacific Biosciences RSII instrument, using two RSII SMRTcells v3 and P6-C4 chemistry (PacBio, Earlham Institute provider). Each cell was sequenced using a 240minute movie, using the Magbead OCPW v1 protocol (PacBio).

(iv) Medkleb genome assembly. The Medkleb genome was assembled according to the Hierarchical Genome-Assembly Process (HGAP.3) protocol (Chin et al. 2013) as follows. 1) Mapping - BLASR (Chaisson et al., 2012) was used to map reads $>500$ bp with a read quality $>0.8$ to seed reads $>6000$ bp. 2) Pre-assembly - the Directed Acyclic Graph Consensus (DAGCon) algorithm (Lee et al 2002) was used to produce a consensus sequence based on BLASR mapping. DAGCon then trimmed the consensus, producing an error-corrected pre-assembled read. 3) de novo genome assembly - the overlap-layout-consensus assembler Celera Assembler v8.1 was used to process the pre-assembled read into a draft assembly. 4) Final consensus - the draft assembly was polished using the Quiver multiread consensus algorithm (Chin et al 2013). 5) The final consensus sequence was then manually trimmed to circularise the genome and place the stop codon (TGA) of the dnaA gene at the 5 ' terminus.

(v) Medkleb genome quality control. An estimated Quiver quality value (QV) for the Medkleb final consensus genome was provided (Earlham Institute). Genome completeness was estimated with both benchmarking universal single copy orthologues (BUSCO) software 3.0.0 (Simão et al 2015), and CheckM (Parks et al 2015). The Enterobacteriales order and Enterobacteriaceae family were 
used as reference datasets for BUSCO and CheckM analyses respectively. Genome contamination was estimated with CheckM, and mlplasmids (Arredondo-Alonso et al 2018) was used to classify contigs as either chromosomal or plasmid DNA. The Klebsiella pneumoniae support-vector machine (SVM) model was utilised for the analysis, with minimum posterior probability specified at 0.7 and minimum contig length at 1,000 nt.

(vi) Annotation and genome mapping. Coding sequences within the Medkleb chromosomal DNA and plasmids, were called with the Prodigal algorithm (Hyatt et al 2010). Gene calls were then annotated with Classic-RAST (Overbeek et al 2014). Ribosomal RNAs (rRNAs) and transfer RNAs (tRNAs) were called and annotated with Classic-RAST. Circular maps were created for the Medkleb chromosomal DNA and plasmids using DNAplotter (Carver et al 2009).

\section{Phylogenetic analyses of the Medkleb Klebsiella gut symbiont genome sequence}

(i) $16 s$ rRNA gene sequence analyses. The Medkleb genome was searched for regions homologous to the 16S rRNA gene sequence of $K$. oxytoca strain ATCC 13182 (NR_118853.1) with BLASTn (Altschul et al 1997). The region with greatest homology to NR_118853.1 (nts 341370-342821) was then parsed with RNAmmer 1.2 (Lagesen et al 2007) which predicts ribosomal genes. Sixty-one $16 \mathrm{~S}$ rRNA gene nucleotide sequences representing 60 Klebsiella strains, Pseudomonas aeruginosa strain JB2 and a putative Medkleb 16S sequence were used to create a phylogeny with the SILVA ACT web app (Pruesse et al 2012). Where possible, non-redundant sequences were extracted from the SILVA rRNA gene database (Quast et al 2013). All sequences were almost complete (>1400bp) and met the standard operating procedure for phylogenetic inference (SOPPI) quality criteria set out by Peplies et al. (Peplies et al 2008). The tree was computed with the FastTree2 maximum likelihood programme (Price et al 2010) using the GTR evolutionary model and gamma distribution parameters (Yang 1994). The resulting phylogeny was constructed with FigTree 1.4.3 (Rambaut and Drummond 2009).

(ii) Average Nucleotide Identity (ANI) analyses. 35 RefSeq whole genome entries extracted from the NCBI database (Geer et al 2010), representing four Klebsiella species, were used to calculate a hierarchical clustering based on Average Nucleotide Identity (Konstantinidis and Tiedje 2005). The ANI Calculator (Figueras et al 2014) was used to compute the hierarchy using the BIONJ algorithm (Gascuel 1997). The tree was constructed with FigTree 1.4.3 (Rambaut and Drummond 2009). To predict recently acquired Medkleb sequences, the genome was aligned with three closely related bacteria. Genomes were manually re-ordered to place the dnaA stop codon at the 5 ' terminus. Synteny was then predicted with progressive Mauve (Darling et al 2010).

\section{Metabolic functions of the Medkleb Klebsiella gut symbiont}

(i) Analysis of pectinolytic enzyme activity. Medkleb's ability to degrade pectin was compared to two bacterial species identified as positive and negative controls; Erwinia carotovora (+ve control) and 
312 Rhizobium leguminosarum (-ve control) (Wegener 2002; Xie et al 2012). Medkleb bacteria were

313 cultured in LB broth $(5 \mathrm{~g} / \mathrm{L} \mathrm{NaCl} ; 5 \mathrm{~g} / \mathrm{L}$ yeast extract; $1.5 \mathrm{~g} / \mathrm{L}$ glucose; $10 \mathrm{~g} / \mathrm{L}$ tryptone) which had been

314 stored in $50 \mathrm{ml}$ glass bottles and autoclaved prior to use. Each bottle was inoculated with a "loop" of

315 bacteria and incubated, shaking, in an orbital incubator (New Brunswick Scientific Innova 44) at

316 200RPM. Medkleb and Erwinia carotovora were incubated at $37^{\circ} \mathrm{C}$ and Rhizobium leguminosarum

317 was incubated at $28^{\circ} \mathrm{C}$ until optical density was greater than 1.0 at $600 \mathrm{~nm}$.

319 (ii) Analysis of presence of pehX and 16S rRNA genes in medkleb. Bacterial DNA was extracted 320 using a DNeasy blood and tissue kit (Qiagen) and microbe lysis buffer (MLB) $(20 \mathrm{mg} / \mathrm{ml}$ of lysozyme 321 (Sigma) and $5 \mathrm{mg} / \mathrm{ml}$ of achromopeptidase (Sigma) in $20 \mathrm{mM}$ Tris-HCl, $2 \mathrm{mM}$ EDTA, 1.2\% Triton X $322(\mathrm{pH} 8.0)$ ). $2 \mathrm{ml}$ of Medkleb, Erwinia carotovora and Rhizobium leguminosarum cultures were 323 centrifuged at 13K RPM for 5 mins, before the supernatants were removed. Pellets were then

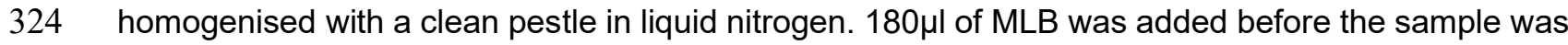
325 vortexed and incubated at $37^{\circ} \mathrm{C}$ for two hours. Samples were vortexed every 30 mins during the two326 hour incubation. Buffer $A L$ and ethanol were mixed 1:1 (Buffer $A L E$ ) and warmed to $55^{\circ} \mathrm{C}$. Each 327 sample had $400 \mu$ l of warm Buffer ALE added before being immediately vortexed for 10-15 secs. 328 Samples were transferred to a spin column and centrifuged at 8000RPM for 60 secs. 500 $\mu$ of Buffer 329 AW1 was added and the sample was centrifuged again at 8000RPM for 60 secs. $500 \mu l$ of Buffer 330 AW2 was added and the samples were centrifuged at 13000 RPM for 4 mins. 35 $\mu$ l of warm Buffer $331 \mathrm{AE}\left(60^{\circ} \mathrm{C}\right)$ was added to the centre of the spin membrane and the samples were centrifuged at 332 6000RPM for 60 secs. DNA purity and concentration were measured using a Nanodrop 333 (ThermoFisher). The $K$. oxytoca polygalacturonase gene pehX (AY065648.1) was aligned to 334 genomes of Klebsiella bacteria using BLAST (Altschul et al 1997). The presence of 335 polygalacturonases in genomes of Klebsiella bacteria was assessed using the Carbohydrate-Active enZymes database (CAZy) (Lombard et al 2010).

(iii) Polygalacturonase enzyme assay. Polygalacturonase production of Medkleb, Erwinia carotovora and Rhizobium leguminosarum was measured using a DNS colorimetric method (Miller 1959) with

340 a protocol adapted from Sohail et al. (Sohail and Latif 2016) and Sigma Aldrich protocol EC 3.2.1.1. 341 Cultures were diluted with LB broth to an optical density of 1.0 at $600 \mathrm{~nm}$. Bacteria were then filtered 342 from culture media with $0.2 \mu \mathrm{m}$ PES syringe filters (ThermoFisher). Treatment reactions (which were 343 run in triplicate) were set up with $1 \mathrm{ml}$ of appropriate filtrate and $1 \mathrm{ml}$ of polysaccharide solution (PS) 344 (0.9\% polygalacturonic acid (ThermoFisher) in $0.1 \mathrm{M}$ sodium acetate (ThermoFisher) $(\mathrm{pH} 4.5))$, a 345 blank reaction was set up with $1 \mathrm{ml}$ of PS only. All reactions were incubated at $45^{\circ} \mathrm{C}$ for $30 \mathrm{mins}$ before $3461 \mathrm{ml}$ of colour reagent solution ( $20 \% 5.3 \mathrm{M}$ potassium sodium tartrate, tetrahydrate in $2 \mathrm{M}$ sodium 347 hydroxide solution; $50 \% 96 \mathrm{mM}$ 3,5-Dinitrosalicylic acid solution; $30 \%$ molecular water 348 (ThermoFisher)) was added. All reactions were incubated at $100^{\circ} \mathrm{C}$ for 15 mins, then placed on ice 349 to cool to room temperature. Once cooled, $12 \mathrm{ml}$ of molecular water (ThermoFisher) was added to 
350 each reaction, followed by hand mixing. Absorbance at 530nm ( $\triangle \mathrm{A} 530$ ) was measured using a

351 spectrophotometer (Biochrom) which had been blanked for air, with the corrected $\Delta \mathrm{A} 530$ for

352 treatment reactions being calculated as:

$\triangle A 530($ Treatment reaction $)=\Delta A 530$ (Treatment reaction $)-\triangle A 530$ (Blank reaction)

354 Units of polygalacturonase in the filtrate were calculated via comparison to a standard curve of 355 galacturonic acid (Sigma). Standards were made with between $50 \mu \mathrm{l}$ and $1 \mathrm{ml}$ of monosaccharide 356 solution (MS) (1.8\% galacturonic acid (ThermoFisher) in $0.1 \mathrm{M}$ sodium acetate (ThermoFisher) $(\mathrm{pH}$ 357 4.5) and topped up to $2 \mathrm{ml}$ total volume with molecular water (ThermoFisher). A standard blank was 358 set up containing $2 \mathrm{ml}$ of molecular biology grade water only. $1 \mathrm{ml}$ of colour reagent solution was then 359 added before incubation at $100^{\circ} \mathrm{C}$ for 15 mins. Standards were placed on ice to cool to room 360 temperature before $12 \mathrm{ml}$ of molecular water was added and $\triangle \mathrm{A} 530$ was measured using a 361 spectrophotometer (Biochrom) which had been blanked for air. The corrected $\triangle \mathrm{A} 530$ for standards 362 was calculated as: $\triangle A 530$ (Standard) $=A 530$ (Standard) $-A 530$ (Blank). The standard curve was 363 used to estimate $\mathrm{mg}$ of galactose released in treatment reactions with linear regression, and units of 364 polygalacturonase per $\mathrm{ml}$ of filtrate were then calculated as: Units $/ \mathrm{ml}$ enzyme $=$ ( $\mathrm{mg}$ of galactose 365 released) $/ \mathrm{ml}$ of filtrate).

(iv) Prediction of higher order metabolic functions and secondary metabolites. The higher order metabolic functions of genes were predicted using the Kyoto Encyclopaedia of Genes and Genomes (KEGG) (Kanehisa et al 2016). Secondary metabolites were predicted using antiSMASH 6.0 beta (Blin et al 2019). 


\section{Results}

\section{Characterisation of the medfly gut microbiome using amplicon sequencing}

(i) Bacterial community diversity. We found that OTU richness and diversity varied significantly among host samples according to treatment and origin (Figure $1 \mathrm{~A} \& \mathrm{~B}$ ). Community structure (beta diversity) was affected primarily by diet, in both wild and lab flies (PERMANOVA: $F_{8,48}=2.74, P$ $<0.001, R^{2}=0.27$, Figure $\left.1 A\right)$. Within lab flies, age $\left(F_{1,30}=4.9, P<0.001, R^{2}=0.18\right)$, diet $\left(F_{3,30}=2.03\right.$, $\left.P=0.023, R^{2}=0.12\right)$, and antibiotic treatment $\left(F_{1,30}=4.9, P=0.002, R^{2}=0.09\right)$, all affected community structure, with decreasing levels of effect. Bacterial species diversity (alpha diversity) did not vary significantly in the wild or laboratory population strains but was lower in antibiotic treated flies. However, the Shannon index was not significantly different between any samples (Figure 1B). Overall, we found no evidence of large-scale changes in diversity or composition of the microbiome despite testing multiple wild food sources, effects of laboratory diets and antibiotic treatment (Figure $1 \mathrm{C})$.

(ii) Dominant bacterial taxa. Four bacterial families representing two bacterial phyla made up over $90 \%$ of the sequences in our dataset. These were the Proteobacteria, Enterobacteriaceae (79\%), Moraxellaceae (2.3\%) and Xanthomonadaceae (3.6\%), and the Firmicutes, Enterococcus (7.3\%) (Figure 1C). Of these, a single bacterial genus Klebsiella spp emerged as a core member of the bacterial microbiome. A putative Klebsiella spp was found in every medfly population sample and comprised $73.6 \%$ of the entire dataset. This suggests that, although medflies are extremely polyphagous, they have a stable microbiome, containing a recurrent Klebsiella spp symbiont. 
A

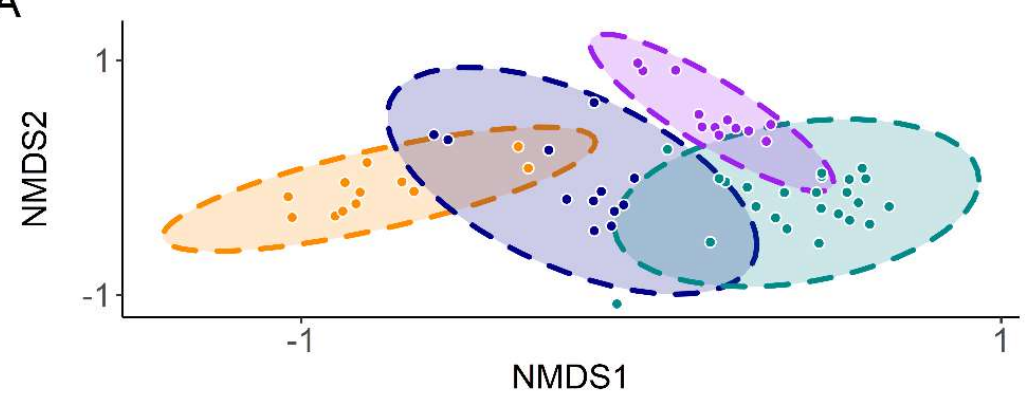

B

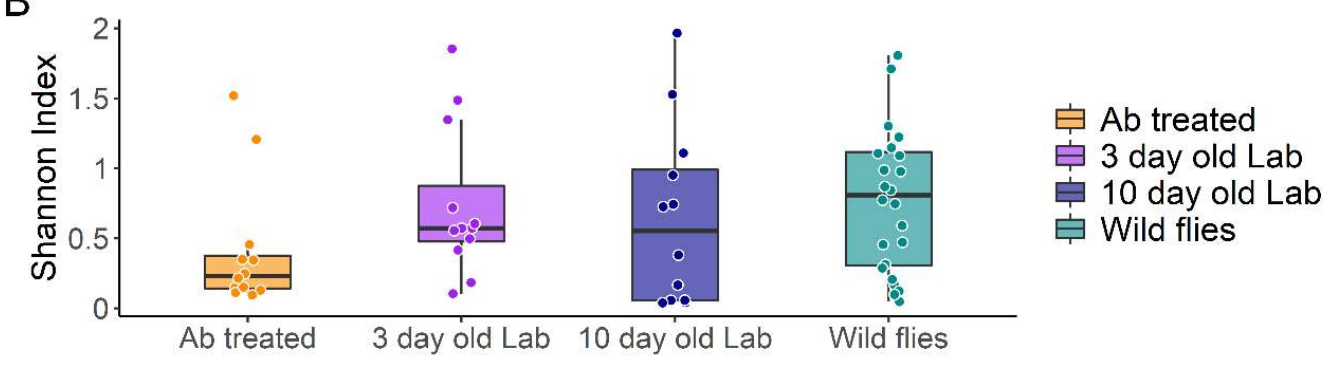

C

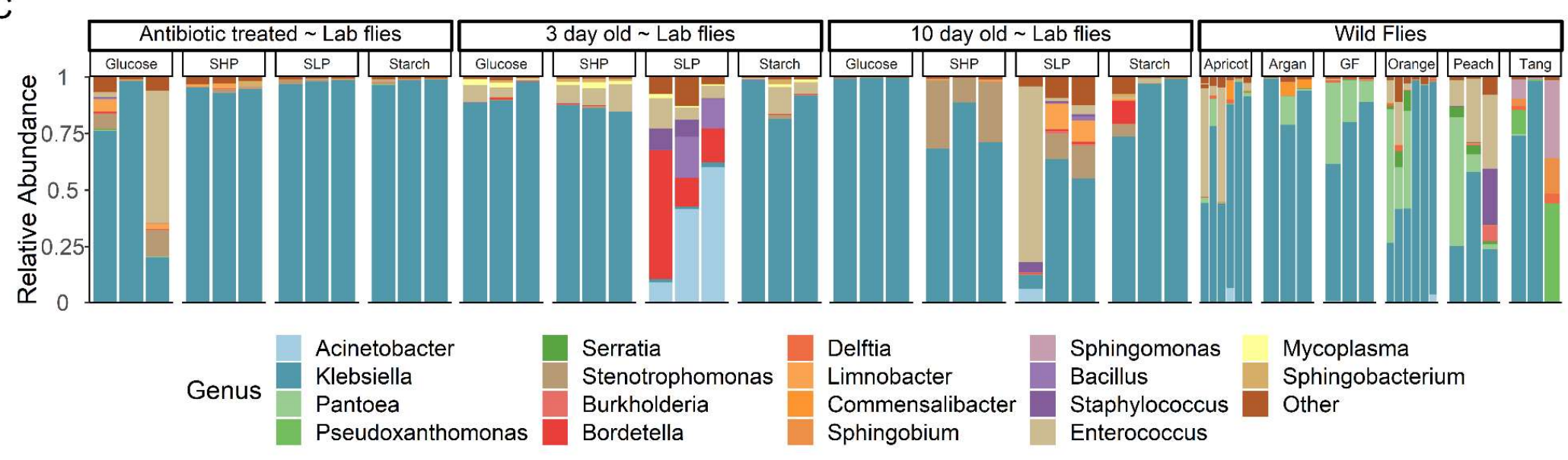

Figure 1. 16S rRNA profiles of wild and laboratory strains of medfly on varied larval diets and in the presence and absence of antibiotic treatment. Microbiome composition was measured as (A) community structure/beta diversity visualised as NMDS plots using a Bray-Curtis Dissimilarity Index with 95\% confidence ellipses, (B) species richness/alpha diversity using the Shannon Index. Boxplot displays median, hinges are first and third quartiles, whiskers extend from 401 hinge to $1.5^{\star}$ the interquartile range. (C) Bar plot of microbiome profiles. Ab = antibiotic treated $(100 \mu \mathrm{g} / \mathrm{ml} \mathrm{kanamycin,} 200 \mu \mathrm{g} / \mathrm{ml}$ ampicillin, $200 \mu \mathrm{gg} / \mathrm{ml} \mathrm{streptomycin}$, $50 \mu \mathrm{g} / \mathrm{ml}$ chloramphenicol, $100 \mu \mathrm{g} / \mathrm{ml}$ apramycin, $100 \mu \mathrm{g} / \mathrm{ml}$ hygromycin and $200 \mu \mathrm{g} / \mathrm{ml}$ tetracycline), 3 day old Lab $=3$ day old adults from the Toliman laboratory 403 strain; 10 day old $\mathrm{Lab}=10$ day old adults from the Toliman laboratory strain, wild flies = flies from fallen argan fruit in Arzou, Ait Melloul, Morocco; Apricots, Oranges and Grapefruits in Chania, Crete; and from Peaches, Oranges and Tangerines in Ano Lechonia, Greece ( $\mathrm{n}=5$ flies per replicate, 3 biological replicates) 
405

406

407

408

409

410

411

412

413

414

415

416

\section{Medkleb genome sequencing}

(i) Classification of Medkleb sequencing contigs. Total Medkleb DNA was sequenced on a PacBio RSII module and assembled using the HGAP.3 algorithm and Quiver (Chin et al., 2013). This process detected one large contig that sequestered $94 \%$ of total gene space (Figure 2) and four small contigs (mkp1-4; Figure S1). This suggests that the total Medkleb DNA complement is formed of one chromosome and four plasmids. Consistent with this, the mlplasmids software (ArredondoAlonso et al., 2018) classified the large Medkleb contig as chromosomal and the four smaller contigs as plasmids (Table S2). In addition, mkp2, mkp3 and mkp4 were sequenced with relatively high coverage depth (Figure S2) and showed evidence for high copy numbers, a common plasmid trait (Providenti et al., 2006). Finally, mkp3 and mkp5 were demonstrated to have low GC content relative to the putative chromosome (Table S2), which again is characteristic of plasmid DNA (Nishida 2012). mkp2 and mkp4 both exhibited a similar GC content to that of the chromosome, suggesting that they have been acquired more recently (Rocha and Danchin 2002).

(ii) Quality control. PacBio coverage depth $>100 \mathrm{X}$ is considered sufficient for resolving nucleotide sequences (Rhoads et al., 2015) and this threshold was met by all contigs other than mkp4 (Figure S2). The QV sequence resolution was 48.9 (an average error rate of 1 base in every 80100) and hence the Medkleb chromosome was of high quality (Figure S2). The plasmid QV's were: mkp1) 48, mkp2) 47.3, mkp3) 45.3 and mkp4) 44.8 (Figure S2). Although the plasmid sequences had lower resolution, they were robust, with accuracy $>99.994 \%$ in all cases. The completeness of the Medkleb genome was measured with BUSCO (Simão et al 2015), which was used to search the assembly for 781 marker genes associated with bacteria of the Enterobacteriales order. BUSCO estimated that the Medkleb chromosomal sequence was 99.5\% complete (777 of 781 genes complete and single copy), far exceeding general quality thresholds (Bowers et al 2017). Furthermore, three genes that were predicted by BUSCO to be fragmented were likely heterozygous alleles that failed to collapse during the annotation. CheckM (Parks et al 2015) was used as a second method to assess the Medkleb chromosome for completeness and contamination. By using as reference 1162 marker genes associated with the family Enterobacteriaceae, the CheckM software estimated that the Medkleb genome was $99.7 \%$ complete and $0.212 \%$ contaminated, again far exceeding standard quality thresholds (Bowers et al 2017).

(iii) Medkleb genome. The general characteristics of the Medkleb genome were consistent with those published as Klebsiella oxytoca (Shin et al 2012; Bao et al 2013). The Medkleb genome was 5825 $435 \mathrm{nt}$ in length, with 5388 coding sequences and a GC content of $56.03 \%$ (Figure 2; Table S3). At $87.8 \%$, overall coding sequence was within the expected range (Kuo et al 2009), and, as predicted by Reva et al. (2004), genes were distributed symmetrically between the two DNA strands. There were 2541 coding sequences on the positive strand, which were predicted to code for 2473 proteins, 50 tRNAs and 18 rRNAs. On the negative strand there were 2847 coding sequences which coded for 2805 proteins, 35 tRNAs and 7 rRNAs. KEGG (Kanehisa et al 2016) predicts that the Medkleb 
442 genome encodes for genes with 2842 distinct molecular functions. The genes for 16 (64\%) 443 ribosomal RNAs (rRNA) clustered between nts 62435 - 70701 near the origin of replication (oriC).

444 Medkleb's GC content was $57.28 \%$ for protein coding genes, $53.83 \%$ for rRNA and $58.93 \%$ for tRNA.

445 Consistent with Lobry (1996) GC skew was asymmetric, with an overrepresentation of Gs on the 446 leading strand and Cs on the lagging strand, indicating that the genome is largely stable with few 447 recent recombination events. However, there is one obvious exception, in which GC skew was 448 inverted (>50\% C's) between bases 654 265-677 695. This is indicative of a recent introgression 449 that has resulted in the acquisition of a new gene island (designated GI1) (Lawrence and Ochman 450 1997; Wixon 2001).

451 (iv) Medkleb plasmids. The lengths and GC contents of mkps 1-4 (Table S2) were all within 452 expected range for plasmids associated with Klebsiella oxytoca. mkps 1-4 are predicted by KEGG 453 (Kanehisa et al 2016) to code for 48 functional orthologues and devote $14-22 \%$ of gene space to 454 plasmid associated genes and mobile element coding sequences. This is substantial in comparison 455 to the main chromosome, which only allocated $0.02 \%$ to such features. mkps 1,3 and 4 exhibited 456 asymmetric gene distribution between DNA strands (coding bias), which is common for plasmid 457 genomes (Reva and Tümmler 2004). The coding bias of mkp3 was particularly clear, with $\sim 90 \%$ of 458 the total gene complement found on the positive strand. mkp4 was the only plasmid predicted by 459 antiSMASH 6.0 beta (Blin et al 2019) to code for secondary metabolites, which included cloacin (de 460 Graaf et al 1969) and colicin bacteriocins (Cascales et al 2007). 
bioRxiv preprint doi: https://doi.org/10.1101/2021.06.09.447743; this version posted June 10, 2021. The copyright holder for this preprint (which was not certified by peer review) is the author/funder, who has granted bioRxiv a license to display the preprint in perpetuity. It is made available under aCC-BY 4.0 International license.

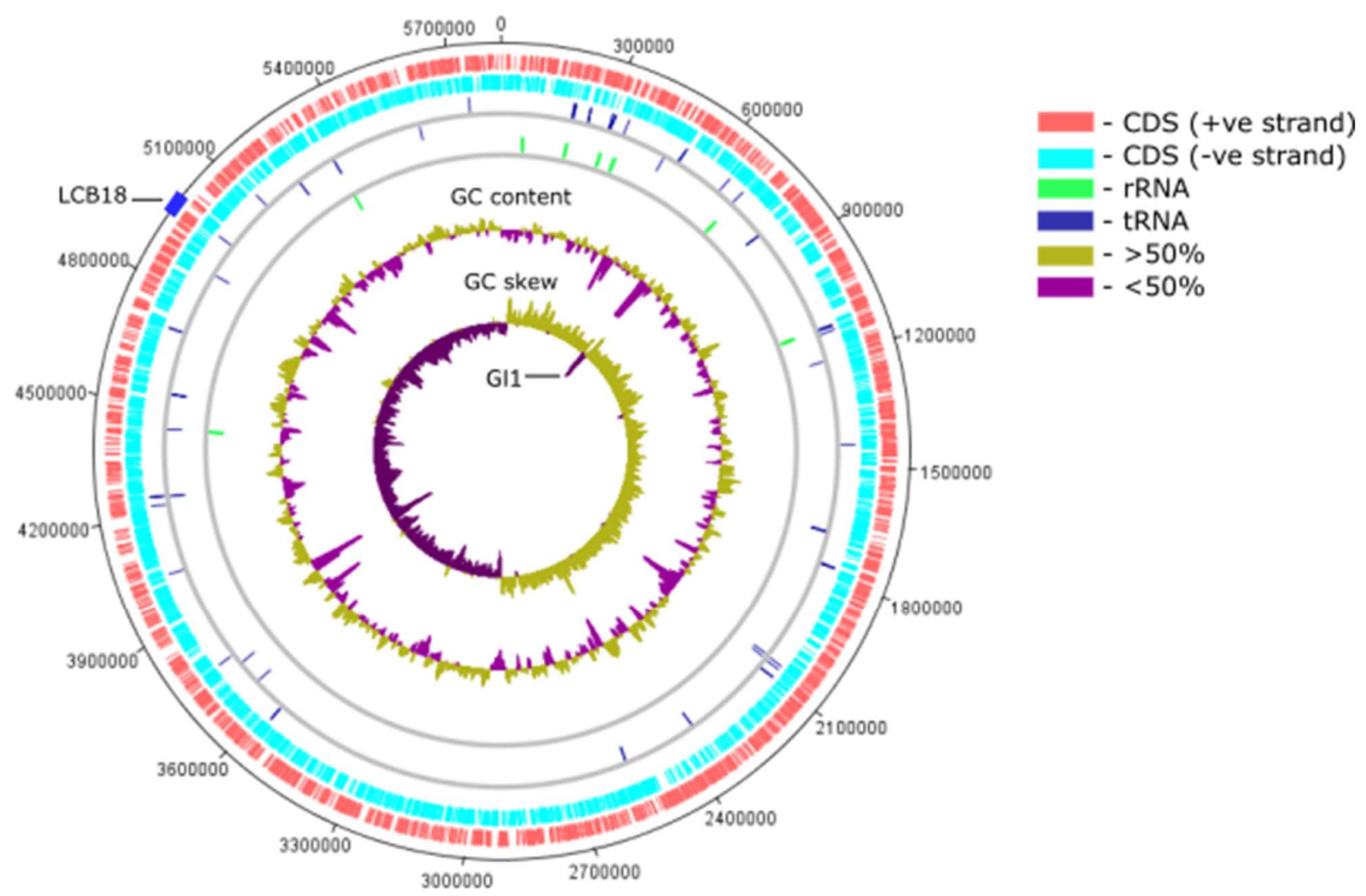

Figure 2. Circular summary map of the Medkleb chromosome. The Medkleb chromosome is represented with the stop codon (TGA) of the $d n a A$ gene at position 0 . Track one; 2541 red ticks represent gene coding sequences on the positive strand. Track two; 2847 light blue ticks represent gene coding sequences on the negative strand. Track three; 50 dark blue ticks above the grey line represent tRNAs on the positive strand, and 35 ticks below the line represent tRNAs on the negative strand. Track four; 18 green ticks above the grey line represent rRNAs on the positive strand, and 7 ticks below the line represent rRNAs on the negative strand. $64 \%$ of rRNAs are found close to oriC. Track five - GC content; regions containing $>50 \%$ GC content are mustard and regions containing $<50 \%$ GC content are purple. Track six - GC skew; regions containing $>50 \%$ Gs are mustard and regions containing $<50 \%$ Gs are purple. GC skew was asymmetric between leading and lagging strands, with the purple spike between bases 654 265-677 695 (GI1) representing recent horizontal gene transfer (Lawrence and Ochman 1997). The LCB18 gene island ( $\approx n t s 4.97 \times 10^{6} \sim 5 \times 10^{6}$ ) is represented by a blue block on the outer ring. 


\section{3. Taxonomic placement of the Medkleb Klebsiella gut symbiont}

477 (i) Taxonomic identification of Medkleb-16S rDNA and ANI analysis. Medkleb was predicted to be 478 a strain of $K$. oxytoca, which has previously been proposed as a major component of the medfly 479 microbiome (Behar et al 2008a). The 16S rRNA gene sequence of $K$. oxytoca strain ATCC 13182 480 (NR_118853.1) was used to locate homologous sequences in the Medkleb genome using the 481 BLASTn algorithm (Altschul et al 1997). This revealed that the Medkleb genome contains eight 482 sequences $>99 \%$ related to NR_118853.1, which were all predicted to code for $16 \mathrm{~S}$ rRNAs by 483 RNAmmer 1.2 (Lagesen et al 2007). Nucleotides 341370-342821 (mk16S) which had the greatest 484 homology with NR_118853.1 were therefore used to represent Medkleb in subsequent taxonomic 485 analyses. These sequences were used in an initial taxonomic description (as described in the 486 Supplementary Information) which indicated that Medkleb was indeed likely to fall within a group of 487 Klebsiella oxytoca / michiganensis spp (Figure S3).

488 A more stringent Average Nucleotide Identity (ANI) (Konstantinidis et al., 2005) analysis was also 489 conducted. The Medkleb genome was positioned in an ANI matrix with 35 RefSeq Klebsiella 490 genomes that were extracted from the NCBI database (Geer et al 2010) (Figure 3). This analysis 491 placed Medkleb in a lineage with 13 strains classified as both $K$. oxytoca and $K$. michiganensis. ANI 492 scores $>95 \%$ are required to classify bacteria as the same species (Richter and Rosselló-Móra 2009; 493 Kim et al 2014). This 95\% similarity threshold was met by all thirteen members of Medkleb's ANI 494 clade (henceforth referred to as the Medkleb group) (Figure S4). Hence both 16S rRNA gene and 495 ANI analyses did not differentiate between $K$. oxytoca and $K$. michiganensis as they are currently 496 named. 
bioRxiv preprint doi: https://doi.org/10.1101/2021.06.09.447743; this version posted June 10, 2021. The copyright holder for this preprint (which was not certified by peer review) is the author/funder, who has granted bioRxiv a license to display the preprint in perpetuity. It is made available under aCC-BY 4.0 International license.

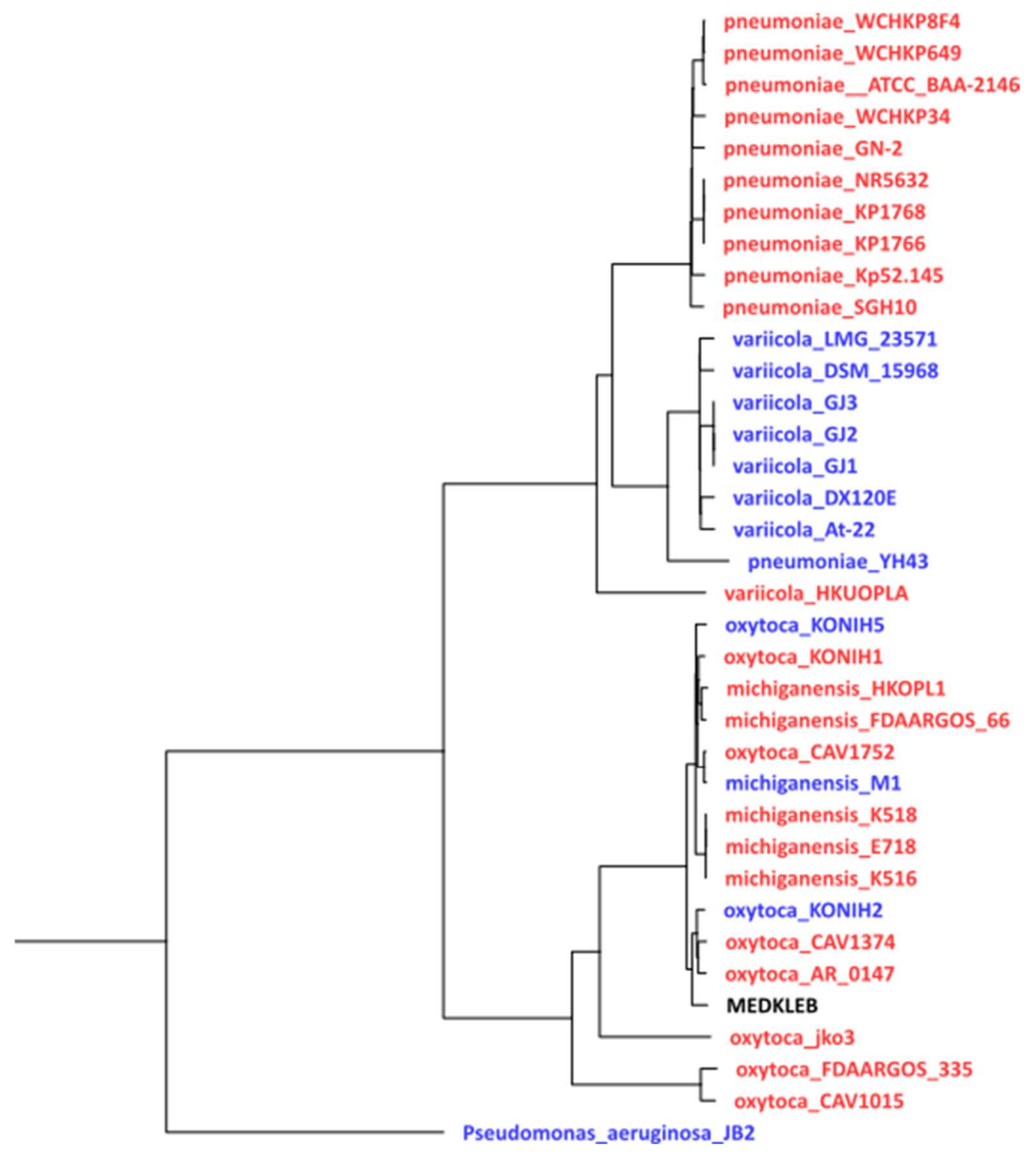

498 Figure 3. ANI hierarchical clustering showing the evolutionary relationship of environmentally-derived and host-derived Klebsiella bacteria. The tree was created using the ANI calculator (Figueras et al 2014), with Pseudomonas aeruginosa strain JB2 selected as the outgroup. Bacteria derived from animal hosts (red and black), and environmentally derived bacteria (blue), generally fell into three clades: 1 ) K. pneumoniae, 2) $K$. variicola and 3) $K$. oxytoca/michiganensis. With one exception in each group (YH43 and HKUOPLA), all $K$. pneumoniae are host derived and all $K$. variicola are environmentally derived. $K$. oxytoca/K. michiganensis have been isolated from both environmental and animal sources, but their sequences did not cluster according to source status. According to the ANI species threshold set by Kim et al. (2014), Medkleb is conspecific with twelve strains which have been classified as both $K$. oxytoca and $K$. michiganensis. 
508

509

510

511

512

513

514

515

516

517

518

519

520

521

522

523

\section{Metabolic functions of the Medkleb Klebsiella gut symbiont}

(i) Bioinformatic analyses of pectic lyases in Medkleb. The ability to degrade pectin is a defining phenotype of $K$. oxytoca and is proposed to be conferred by the polygalacturonase enzyme, pehX (AY065648.1) (Kovtunovych et al 2003) strains of the Medkleb group could be distinguished via homology to pehX but our analysis detected no significant differences between strains (analysed with BLAST; signed-rank linear model $\mathrm{F}_{1,11}=$ $2.57, \mathrm{p}=0.137)$. Unexpectedly, $K$. michiganensis shared greater homology with AY065648.1 than did $K$. oxytoca (Table 1), despite the fact that $K$. michiganensis does not degrade pectin (Saha et al 2013). In addition, the CAZy database (Lombard et al 2010) identified two pectate lyases (one from family 2 and one from family 9 ) in all Medkleb group genomes available on the database (Table S5).

Table 1 Genomic features of the 'Medkleb group' of bacteria. pehX sequence identity (calculated with BLAST (Altschul et al., 1997)) was not significantly different between species (analysed with BLAST; signedrank linear model $\mathrm{F}_{1,11}=2.57, \mathrm{p}=0.137$ ). $\mathrm{K}$. michiganensis genomes contained sequences more closely related to AY065648.1 than was found for $K$. oxytoca genomes (mean relatedness $=88.4 \%$ vs $87.9 \%$ ). All genomes available on the CAZy database (Lombard et al 2010) are predicted to code for 2 pectate lyases. Medkleb had the smallest genome in the group ${ }^{1}$, and the second highest GC content ${ }^{2}$.

\begin{tabular}{|c|c|c|c|c|c|}
\hline Species & Strain & $\begin{array}{c}\text { Genome size } \\
\text { (nt) }\end{array}$ & $\begin{array}{l}\text { GC } \\
(\%)\end{array}$ & $\begin{array}{c}\text { pehX identity } \\
(\%)\end{array}$ & CAZy lyases \\
\hline oxytoca & Medkleb & $5825435^{1}$ & 56.03 & 87.43 & NA \\
\hline michiganensis & M1 & 5865090 & $56.13^{2}$ & 88.47 & 2 \\
\hline michiganensis & HKOPL1 & 5914407 & 55.92 & 88.56 & 2 \\
\hline oxytoca & CAV1752 & 5992008 & 55.16 & 88.47 & 2 \\
\hline michiganensis & $\begin{array}{c}\text { FDAARGOS } \\
66\end{array}$ & 6071464 & 55.94 & 88.39 & NA \\
\hline michiganensis & E718 & 6097032 & 56.02 & 88.31 & 2 \\
\hline michiganensis & K518 & 6138996 & 55.95 & 88.39 & 2 \\
\hline michiganensis & K516 & 6139574 & 55.96 & 88.31 & 2 \\
\hline oxytoca & KONIH1 & 6152190 & 55.91 & 88.61 & 2 \\
\hline oxytoca & KONIH5 & 6179177 & 55.81 & 87.82 & 2 \\
\hline oxytoca & KONIH2 & 6190364 & 55.77 & 87.43 & 2 \\
\hline oxytoca & CAV1374 & 6257473 & 55.75 & 87.87 & 2 \\
\hline oxytoca & AR_0147 & 6350620 & 55.57 & 87.89 & 2 \\
\hline \multicolumn{6}{|c|}{$\begin{array}{l}{ }^{1} \text { smallest genome } \\
{ }^{2} \text { highest GC content }\end{array}$} \\
\hline
\end{tabular}

524

525

526

527

528

529

530

531

(ii) Polygalacturonase enzyme assay. Medkleb was pehX positive when analysed biochemically (Figure S6), which suggested that it should be classified as $K$. oxytoca and can degrade pectin (Kovtunovych et al 2003; Saha et al 2013). We quantified Medkleb's capacity to degrade polygalacturonic acid- in comparison to positive ( $E$ carotovora) and negative ( $R$ leguminosarum) control specimens, using a DNS colorimetric method (Miller 1959). A standard curve of galacturonic acid incubated with DNS (Figure 4A), showed a positive relationship with colour change when the 
532 OD was measured at 530nm (linear model, $F_{1,4}=176.4, p<0.001, R^{2}=0.97$ ). Filtrate of Medkleb and $E$. carotovora culture media both contained pectinolytic enzymes, producing measurable colour change when incubated with polygalacturonic acid and DNS (Figure 4B; (Sohail and Latif 2016)). Medkleb filtrate reduced polygalacturonic acid with around $65 \%$ the efficiency of the Erwinia carotovora, but $R$ leguminosarum filtrate did not demonstrate any measurable pectinolytic activity (Figure 4C). These data support the placement of Medkleb as K. oxytoca.

(iii) Predicted metabolic functions of Medkleb. KEGG (Kanehisa et al 2016) was used to produce a list of gene functions for chromosomes and plasmids associated with all $K$. oxytoca bacteria in the Medkleb group (Table S5). The dataset was filtered to produce three smaller lists: 1) Atypical - gene functions unique to Medklebn, 2) Absent - gene functions present in all genomes analysed other than Medkleb, 3) Duplicated - gene functions encoded in multiple copies by Medkleb but not by any other genome analysed The Medkleb genome contained 21 atypical functional orthologues (Figure S7), and of these, 16 were chromosomally derived and five located on plasmids. The atypical genes included two putative transposases, enzymes involved in various modes of metabolism (e.g., $m$ tIA, $A C A D S B$, egsA, $F A A H 2$ ) and four transport protein genes (e.g. natA \& gatC). When compared to conspecifics, Medkleb has 35 absent gene functions, seven of which may indicate adaptation to the relatively innoxious medfly gut (Figure S8). The largest cluster of absent genes was associated with copper resistance (copB, cusS, cusR, cusC, cusF) and genes that degrade arsenic (arsB) and nitriles (nthA) were also missing. The Medkleb genome codes for multiple copies of 11 functional orthologues, that other $K$. oxytoca bacteria in the Medkleb group retain in single copy at most (Figure S9). Medkleb's duplicated genes may have the potential to promote mutualistic phenotypes for the acids $(A C A T)$ and citrate (citE).

(iv) Secondary metabolites. The Medkleb genome and plasmid sequences were interrogated using antiSMASH 6.0 beta (Blin et al 2019) for the presence of novel secondary metabolites. Chromosomes of all K. oxytoca members of the Medkleb group (other than KONIH2) coded for three common secondary metabolite clusters: 1$)$ non-ribosomal polypeptide synthetase $(30 \%$ similarity to turnerbactin), 2) thiopeptide antibiotic (14\% similarity to O-antigen), 3) Ribosomally synthesized and post-translationally modified peptides (RiPPs). The Medkleb chromosome contained two unique secondary metabolite clusters that were not present in any other analysed $K$. oxytoca chromosomes (i) a butyrolactone, a signalling molecule utilised by Streptomyces bacteria to to regulate antibiotic production and cell cycle processes (Takano 2006; Kitani et al 2011), and (ii) an N-acyl amino acid cluster, common to soil dwelling bacteria and involved in cell-to-cell communication (Craig et al 2011; Battista et al 2019) (Table 2). Plasmid mkp4 was also predicted to code for cloacin and colicin bacteriocins that were not coded by any other $K$. oxytoca strain in the Medkleb group. The cloacin 
bioRxiv preprint doi: https://doi.org/10.1101/2021.06.09.447743; this version posted June 10, 2021. The copyright holder for this preprint (which was not certified by peer review) is the author/funder, who has granted bioRxiv a license to display the preprint in perpetuity. It is made available under aCC-BY 4.0 International license.
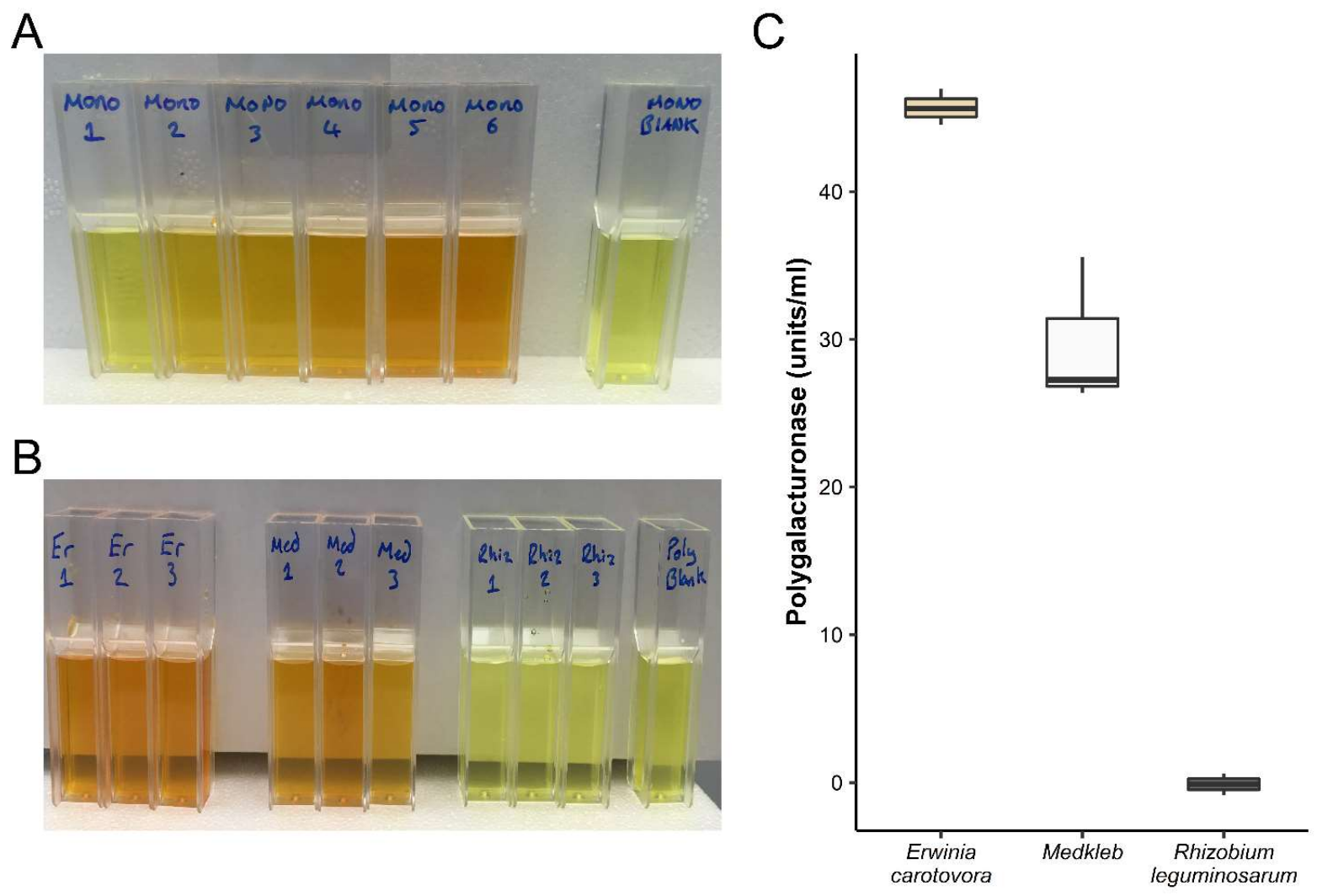

Figure 4. Polygalacturonase production by Erwinia carotovora (Er), Medkleb (Med) and Rhizobium leguminosarum (Rhiz). A) Monosaccharide colorimetric reaction mixtures, standard curve - The quantity of sugar in standards ranged from $0.9 \mathrm{mg}$ (mono 1 ) to $18 \mathrm{mg}$ (mono 6). Mono blank contained no sugar. When incubated with DNS, colour change (measured at $\triangle \mathrm{A} 530$ ) occurred for all reactions relative to the blank. The relationship between sugar quantity and colour change was significant (linear model, $F_{1,4}=176.4, p<0.001$, $\mathrm{R}^{2}=0.98$ ). B) Bacteria reaction mixtures - Polygalacturonase production of three bacteria, Erwinia carotovora (Er), Medkleb (Med) and Rhizobium leguminosarum (Rhiz) was measured via the quantity of reduced sugar in solution, following incubation of culture filtrate with polygalacturonic acid. Units of polygalacturonase were quantified in terms of colour change via extrapolation from the standard curve. Med and Er filtrate contained 30 and 46 units of polygalacturonase per $\mathrm{ml}$ respectively. Rhiz filtrate did not contain any polygalacturonase. C) Units of polygalacturonase contained in bacterial filtrate. Units of polygalacturonase per $\mathrm{ml}$ are represented on the $y$-axis. 1000ul aliquots of bacterial filtrate processed from three different species of bacteria are represented of the $\mathrm{x}$-axis. Bacteria were assessed for the presence of polygalacturonases using a standard curve of galacturonic acid. The upper and lower hinges of boxplots represent the first and third quartiles of enzyme concentrations in filtrate, calculated from three technical replicates. Erwinia carotovora was the highest producer, with an average of $45.7 \mathrm{units} / \mathrm{ml}$ and Medkleb produced polygalacturonase with an average of 29.7 units/ml. Rhizobium leguminosarum did not produce any polygalacturonase. 
589

590

591

592

593

594

595

596

597

598

599

600

601

602

603

604

605

606

607

608

609

610

611

612

613

614

615

616

617

618

619

620

621

622

623

624

\section{Searching for symbiotic signatures in the Medkleb genome}

(i) Genome size and GC content. At 5_825_435bp, the Medkleb genome was the smallest in the 'Medkleb group' and 1.6 standard deviations smaller than the mean genome size of the clade $(n=13)$ $\left(\bar{x}=6.07 \times 10^{6} \mathrm{bp} \pm 1.49 \times 10^{5}\right.$ s.d.). However, we conclude this is not diagnostic of symbiotic transition as the genome of free-living $K$. michiganensis strain $\mathrm{M} 1$, was only $0.7 \%$ larger than Medkleb (5.86 x $\left.10^{6} \mathrm{bp}\right)$. Medkleb's GC content (56.03\%) was also high, even for bacteria with a free-living life history (Moran et al 2008) (Table 1). We conclude that there were no obvious diagnostic signatures of a strong host-association.

(ii) Local genomic rearrangement. The Medkleb genome was aligned, using progressive Mauve (Darling et al 2010) to three closely related strains of K. oxytoca (Figure S5). This analysis revealed the presence of 21 local colinear blocks (LCBs) of conserved DNA in all four genomes (Figure S5).

These LCBs were not uniformly distributed between the genomes. K. oxytoca strains AR0147 and CAV1374 both contained inversions between LCBs 11-16 and strain KONIH2 contained several instances of translocation and inversion. However, despite inversion and translocation events, nucleotide sequence in all LCBs other than LCB18 was very highly conserved. The annotation of Medkleb LCB18 ( $\approx$ nts $4.97 \times 10^{6} \sim 5 \times 10^{6}$ ) predicts 25 coding sequences in total, including 13 "hypothetical proteins", 2 DNA helicases (Mkleb_4576/4577), 2 methyltransferases (Mkleb_4579/4597) and an anti-restriction protein (Mkleb_4581). LCB18 may have been recently acquired as it also contains genes associated with horizontal transfer including an integrase (Mkleb_4574), a mobile element protein (Mkleb_4594) and a prophage protein (Mkleb_4585). In addition, two hypothetical proteins encoded by LCB18 (MKleb_4591 \& Mkleb_4592) may be virulence factors, as they are predicted by TMHMM $2.0\{$ Krogh, 2001) to encode N-terminal peptides. However, there is as yet no definitive evidence that LCB18 contains genes that might confer fitness to the medfly (Table 2).

The Medkleb genome carries an inversion of GC skew on the leading strand ( $>50 \%$ C; region GI1) indicating a putative horizontal gene transfer event. GI1 is thought to have been transferred from a plasmid, as it codes for TraY which facilitates plasmid conjugal transfer (Nelson et al 1995). Though plasmid integration into host chromosome is common (Dobrindt et al 2004; Bire and Rouleux-Bonnin 2012), GI1 does not appear to have integrated from any of the Medkleb plasmids (mkps 1-4) (Table 2). In total GI1 is predicted to code for 25 proteins including Bll0873, first sequenced in Bradyrhizobium diazoefficiens, a bacterium that is a known nitrogen fixing symbiont of legumes (Kaneko et al 2002). Interestingly, both GI1 (Mkleb_0586) and LCB18 (Mkleb_4596) code for genes predicted to facilitate molybdopterin biosynthesis, which could have the potential to benefit the medfly host, as this group of co-factors aid nitrate reduction (Moreno-Vivián et al 1999). 
bioRxiv preprint doi: https://doi.org/10.1101/2021.06.09.447743; this version posted June 10, 2021. The copyright holder for this preprint (which was not certified by peer review) is the author/funder, who has granted bioRxiv a license to display the preprint in perpetuity. It is made available under aCC-BY 4.0 International license.

625 According to KEGG analysis, the Medkleb genome contains coding sequences for 21 atypical

626 functional orthologue genes that are not encoded in the genomes of any other closely related

627 Klebsiella bacteria in the Medkleb group (Table 2). Some of these are potentially mutualistic

628 functions such as sugar metabolism $(m t / A)$ and nitrogen fixation ( $n i f Z)$. Medkleb also has duplicates

629 of 11 functional orthologues that $K$. oxytoca generally retains in only single copy. These duplicated

630 functional orthologues do not cluster by genomic location. Several of these duplicated gene functions

631 have strong mutualistic potential such as the biosynthesis of amino acids (proC, $\operatorname{trpA}$ ) and

632 breakdown of essential nutrients (cite, pydC). In contrast, Medkleb is also missing some clusters of

633 genes that are present in closely related bacteria, e.g. for specific enzymes related to copper

634 resistance (copB, cusS, cusR, cusC, cusF) and phosphonate transport (phnC, phnD, phnE).

635 Table 2 Unique features of the Medkleb genome in comparison to conspecifics.

\begin{tabular}{|c|c|c|}
\hline Unique feature & Identified via & Possible mutualistic function \\
\hline$\angle C B 18$ & $\begin{array}{l}\text { progressiveMauve } \\
\text { analysis of Medkleb and } \\
\text { three conspecifics }\end{array}$ & $\begin{array}{l}\text { Codes for genes related to molybdopterin } \\
\text { biosynthesis and several proteins with } \\
\text { unknown function. These genes may confer } \\
\text { fitness to the medfly. }\end{array}$ \\
\hline G/1 & Inversion of GC skew & $\begin{array}{l}\text { Codes for genes related to molybdopterin } \\
\text { biosynthesis and several proteins with } \\
\text { unknown function. These genes may confer } \\
\text { fitness to the medfly. }\end{array}$ \\
\hline $\begin{array}{l}\text { Atypical } \\
\text { metabolic } \\
\text { genes }\end{array}$ & $\begin{array}{l}\text { Comparison of KEGG } \\
\text { gene functions between } \\
\text { Medkleb group } \\
\text { members. }\end{array}$ & $\begin{array}{l}m t I A, A C A D S B, \text { egs } A \text { and } F A A H 2 \text { expand } \\
\text { the range of nutrients available to the } \\
\text { medfly. }\end{array}$ \\
\hline $\begin{array}{l}\text { Absent sensory } \\
\text { genes }\end{array}$ & $\begin{array}{l}\text { Comparison of KEGG } \\
\text { gene functions between } \\
\text { Medkleb group } \\
\text { members. }\end{array}$ & $\begin{array}{l}\text { The medfly gut may be relatively non-toxic } \\
\text { allowing Medkleb to survive without genes } \\
\text { that detect and metabolise certain chemical } \\
\text { threats in its environment (copB, cusS, } \\
\text { cusR, cusC, cusF, arsB, nthA). }\end{array}$ \\
\hline $\begin{array}{l}\text { Duplicated } \\
\text { genes }\end{array}$ & $\begin{array}{l}\text { Comparison of KEGG } \\
\text { gene functions between } \\
\text { Medkleb group members }\end{array}$ & $\begin{array}{l}\text { Duplication of } 11 \text { genes associated with } \\
\text { biosynthesis of amino acids and breakdown } \\
\text { of essential nutrients. These genes may } \\
\text { confer fitness to the medfly by providing } \\
\text { access to extra nutritional resources }\end{array}$ \\
\hline
\end{tabular}




\begin{tabular}{lll}
\hline Unique feature & Identified via & Possible mutualistic function \\
\hline $\begin{array}{l}\text { Butyrolactone } \\
\text { biosynthesis }\end{array}$ & antiSMASH 6.0 beta & $\begin{array}{l}\text { Possible regulation of antibiotic products } \\
\text { (Takano 2006; Kitani et al 2011) }\end{array}$ \\
\hline $\begin{array}{l}\text { N-acyl amino } \\
\text { acid } \\
\text { biosynthesis }\end{array}$ & antiSMASH 6.0 beta & $\begin{array}{l}\text { An important family of endogenous } \\
\text { signalling molecules in which an amide } \\
\text { bond covalently links an amino acid to the } \\
\text { acyl moiety of a long-chain fatty acid. } \\
\text { Primarily involved in cell-to-cell } \\
\text { communication (Craig et al 2011; Battista } \\
\text { et al 2019_ }\end{array}$ \\
& &
\end{tabular}

636

637

638

639

640

641

642

643

644

645

646

647

648

649

650

651

652

653

654

655

656

657

658

659

660

661

662

663

\section{Discussion}

\section{The medfly microbiome}

In this study, we report the use of laboratory and field-reared adult medflies to characterise key features of the bacterial microbiome of this important agricultural pest. Using analyses of $16 \mathrm{~S}$ rRNA gene amplicon sequencing of culturable and non--culturable members of the gut microbiome, we found that overall species richness was fairly stable between the laboratory-reared flies raised on different diets and the wild medfly samples. Direct comparisons of beta diversity indicated that larval diet, rather than exposure to antibiotics or wild vs lab rearing was the primary driver of microbial diversity of gut microbiomes. Wild flies obtained from distinct geographical regions and different hosts and flies reared on different substrates and exposed to antibiotic cocktails in the laboratory, contained largely the same bacterial families. The data suggest that although medflies are highly polyphagous, they have a stable microbiome that is dominated by the bacterial family Enterobacteriaceae, including a putative symbiont Klebsiella spp. These findings are consistent with previous analyses of medfly microbiomes made using culture-based methods (Behar et al 2005; Behar et al 2008a; Behar et al 2008b; Behar et al 2009a). The picture may be more complex, however, as one recent next-generation sequencing study did not isolate Klebsiella in medfly microbiomes from wild populations (Malacrinò et al 2018), and another identified possible geographic or host-genetic structure links with bacterial dominance (with samples from Greece being dominated by Klebsiella spp) (Nikolouli et al 2020).

\section{Genome sequencing and analysis of the putative Medkleb gut symbiont}

We obtained a fully sequenced Medkleb genome and both 16S rRNA gene and ANI phylogenies identified this as a Klebsiella species (Stackebrandt 2006; Kim et al 2014). Medkleb was pehX positive when analysed with PCR, and a producer of pectinolytic enzymes, both of which support its identification as K. oxytoca (Kovtunovych et al 2003; Saha et al 2013). 
664 Genome size and GC content are generally reduced when a bacterium adopts a facultative lifestyle

665 (McCutcheon and Moran 2011). We found that, although the Medkleb genome was the smallest of 666 all Klebsiella bacteria in the 'Medkleb group', the free-living K. michiganensis strain M1 was only 40 $667 \mathrm{~kb}(0.7 \%)$ larger. The Medkleb GC content was also the second highest in the 'Medkleb group', again 668 counter to what is expected for a facultative mutualist. A strongly symbiotic transition is generally 669 associated with an increased mutation rate, which causes facultative symbionts to occupy extended 670 branches of phylogenetic trees (McCutcheon and Moran 2011). Though Medkleb was slightly distinct 671 from the three bacterial species most closely related to it, it was not markedly so.

672

673 We also used high resolution comparative genetic techniques to test for signals of putative 674 mutualism. These analyses were designed to test: (i) If Medkleb possessed genetic loci/functions 675 that were absent from closely related Klebsiella bacteria and possessed an obvious mutualistic 676 capacity for the fly; (ii) If Medkleb was lacking genetic loci/functions found in all closely related free677 living Klebsiella spp., that would be considered necessary for life in varied environments. Set against 678 this is that gene loss may be unpredictable in the early stages of facultative mutualistic transitions 679 (Moran and Bennett 2014).

Comparative genomics highlighted that the Medkleb genome contained two discrete regions (GI1 and LCB18) which may have been acquired comparatively recently and are not typically found in $K$. oxytoca. Both GI1 and LCB18 contain genes associated with horizontal transfer and encode several unannotated hypothetical proteins with mutualistic potential. Medkleb was demonstrated to be functionally pectinolytic and global gene function analyses highlighted several more atypical functions were encoded exclusively by Medkleb in comparison to conspecifics. These atypical genes are dispersed throughout the genome which suggests that they are ancestral and not recently inherited. Some of these genes are predicted to encode metabolic enzymes that could allow the medfly to utilise otherwise unattainable nutrients. In addition, Medkleb has several duplicated genes that are randomly distributed throughout the genome which could provide the medfly with beneficial nutrients and amino acids. Together, these genomic signatures suggest that Medkleb is a symbiont that improves host fitness through increased access to vital nutrients. If substantiated, this could help to partially explain the success of the medfly as a generalist pest. However, potentially mutualistic traits are not evidence of mutualism itself and many signals that are commonly associated with facultative mutualism are not evident in the Medkleb genome. Therefore there is insufficient evidence, so far, to definitively classify Medkleb as a facultative mutualist of the medfly. 2012). Therefore, Medkleb might provide a platform for paratransgenic control of the medfly. This 
702 genome of a putative symbiont. Future studies should sample all developmental stages of the

703 medfly, and sample more intensively to establish the potential for phylosymbiosis. Complementing

704 this should be experimental studies to establish localisation of Klebsiella within the medfly gut, to

705 determine transmission mechanisms and assess metabolic communication and host benefit

706 (Leftwich et al 2020).

707

\section{Data Deposition:}

709 Sequencing data has been submitted to the NCBI Sequence Read Archive and is available under 710 BioProject ID PRJNA638617.

711

\section{Acknowledgements}

713 This work was funded by the Biotechnology and Biological Sciences Research Council Research

714 (Grant BB/K000489/1 to T.C., P.T.L., and M.I.H. and PhD studentship to M.D). We also thank

715 Kostas Voudouris, Romisa Asadi \& Martha Koukidou for their help in collecting samples for

716 analysis. 


\section{8}

719

720

721

722

723

724

725

726

727

728

729

730

731

732

733

734

735

736

737

738

739

740

741

742

743

744

745

746

747

748

749

750

751

752

753

754

755

756

757

758

759

760

761

762

763

764

765

766

767

768

769

770

771

772

\section{References}

Aharon Y, Pasternak Z, Ben Yosef M, et al (2013) Phylogenetic, metabolic, and taxonomic diversities shape Mediterranean fruit fly microbiotas during ontogeny. Appl Environ Microbiol 79:303-313. doi: 10.1128/AEM.02761-12

Altschul SF, Madden TL, Schäffer AA, et al (1997) Gapped BLAST and PSI-BLAST: a new generation of protein database search programs. Nucleic Acids Res 25:3389-3402. doi: 10.1093/nar/25.17.3389

Anbutsu H, Moriyama M, Nikoh N, et al (2017) Small genome symbiont underlies cuticle hardness in beetles. Proc Natl Acad Sci USA 114:E8382-E8391. doi: 10.1073/pnas.1712857114

Arredondo-Alonso S, Rogers MRC, Braat JC, et al (2018) mlplasmids: a user-friendly tool to predict plasmid- and chromosome-derived sequences for single species. Microb Genom. doi: 10.1099/mgen.0.000224

Ballinger MJ, Perlman SJ (2017) Generality of toxins in defensive symbiosis: Ribosomeinactivating proteins and defense against parasitic wasps in Drosophila. PLoS Pathog 13:e1006431. doi: 10.1371/journal.ppat.1006431

Bao G, Zhang Y, Du C, et al (2013) Genome Sequence of Klebsiella oxytoca M5al, a Promising Strain for Nitrogen Fixation and Chemical Production. Genome Announc. doi: 10.1128/genomeA.00074-12

Battista N, Bari M, Bisogno T (2019) N-Acyl Amino Acids: Metabolism, Molecular Targets, and Role in Biological Processes. Biomolecules. doi: 10.3390/biom9120822

Behar A, Ben-Yosef M, Lauzon CR, et al (2009a) Structure and function of the bacterial community associated with the Mediterranean fruit fly. Insect Symbiosis

Behar A, Ben-Yosef M, Lauzon CR, et al (2009b) Structure and function of the bacterial community associated with the Mediterranean fruit fly. 251-271.

Behar A, Jurkevitch E, Yuval B (2008a) Bringing back the fruit into fruit fly-bacteria interactions. Mol Ecol 17:1375-1386. doi: 10.1111/j.1365-294X.2008.03674.x

Behar A, Yuval B, Jurkevitch E (2008b) Gut bacterial communities in the Mediterranean fruit fly (Ceratitis capitata) and their impact on host longevity. J Insect Physiol 54:1377-1383. doi: 10.1016/j.jinsphys.2008.07.011

Behar A, Yuval B, Jurkevitch E (2005) Enterobacteria-mediated nitrogen fixation in natural populations of the fruit fly Ceratitis capitata. Mol Ecol 14:2637-2643. doi: 10.1111/j.1365294X.2005.02615.x

Ben Ami E, Yuval B, Jurkevitch E (2010) Manipulation of the microbiota of mass-reared Mediterranean fruit flies Ceratitis capitata (Diptera: Tephritidae) improves sterile male sexual performance. ISME J 4:28-37. doi: 10.1038/ismej.2009.82

Ben-Yosef M, Pasternak Z, Jurkevitch E, Yuval B (2014) Symbiotic bacteria enable olive flies (Bactrocera oleae) to exploit intractable sources of nitrogen. J Evol Biol 27:2695-2705. doi: 10.1111/jeb.12527

Bennett GM, Moran NA (2013) Small, smaller, smallest: the origins and evolution of ancient dual symbioses in a Phloem-feeding insect. Genome Biol Evol 5:1675-1688. doi: 10.1093/gbe/evt118

Bire S, Rouleux-Bonnin F (2012) Transposable elements as tools for reshaping the genome: it is a huge world after all! Methods Mol Biol 859:1-28. doi: 10.1007/978-1-61779-603-6_1

Blin K, Shaw S, Steinke K, et al (2019) antiSMASH 5.0: updates to the secondary metabolite genome mining pipeline. Nucleic Acids Res 47:W81-W87. doi: 10.1093/nar/gkz310

Bosco-Drayon V, Poidevin M, Boneca IG, et al (2012) Peptidoglycan sensing by the receptor PGRP-LE in the Drosophila gut induces immune responses to infectious bacteria and tolerance to microbiota. Cell Host Microbe 12:153-165. doi: 10.1016/j.chom.2012.06.002

Bowers RM, Kyrpides NC, Stepanauskas R, et al (2017) Minimum information about a single amplified genome (MISAG) and a metagenome-assembled genome (MIMAG) of bacteria and archaea. Nat Biotechnol 35:725-731. doi: 10.1038/nbt.3893

Carver T, Thomson N, Bleasby A, et al (2009) DNAPlotter: circular and linear interactive genome visualization. Bioinformatics 25:119-120. doi: 10.1093/bioinformatics/btn578

Cascales E, Buchanan SK, Duché D, et al (2007) Colicin biology. Microbiol Mol Biol Rev 71:158229. doi: 10.1128/MMBR.00036-06 
773

774

775

776

777

778

779

780

781

782

783

784

785

786

787

788

789

790

791

792

793

794

795

796

797

798

799

800

801

802

803

804

805

806

807

808

809

810

811

812

813

814

815

816

817

818

819

820

821

822

823

824

825

826

827

828

Chandler JA, Lang JM, Bhatnagar S, et al (2011) Bacterial communities of diverse Drosophila species: ecological context of a host-microbe model system. PLoS Genet 7:e1002272. doi: 10.1371/journal.pgen.1002272

Chin C-S, Alexander DH, Marks P, et al (2013) Nonhybrid, finished microbial genome assemblies from long-read SMRT sequencing data. Nat Methods 10:563-569. doi: 10.1038/nmeth.2474

Craig JW, Cherry MA, Brady SF (2011) Long-chain N-acyl amino acid synthases are linked to the putative PEP-CTERM/exosortase protein-sorting system in Gram-negative bacteria. J Bacteriol 193:5707-5715. doi: 10.1128/JB.05426-11

Darling AE, Mau B, Perna NT (2010) progressiveMauve: multiple genome alignment with gene gain, loss and rearrangement. PLoS One 5:e11147. doi: 10.1371/journal.pone.0011147

de Graaf FK, Spanjaerdt Speckman EA, Stouthamer AH (1969) Mode of action of a bacteriocin produced by Enterobacter cloacae DF13. Antonie Van Leeuwenhoek 35:287-306.

de Souza DJ, Bézier A, Depoix D, et al (2009) Blochmannia endosymbionts improve colony growth and immune defence in the ant Camponotus fellah. BMC Microbiol 9:29. doi: 10.1186/1471-2180-9-29

Deguenon JM, Travanty N, Zhu J, et al (2019) Exogenous and endogenous microbiomes of wildcaught Phormia regina (Diptera: Calliphoridae) flies from a suburban farm by $16 \mathrm{~S}$ rRNA gene sequencing. Sci Rep 9:20365. doi: 10.1038/s41598-019-56733-z

Dobrindt U, Hochhut B, Hentschel U, Hacker J (2004) Genomic islands in pathogenic and environmental microorganisms. Nat Rev Microbiol 2:414-424. doi: 10.1038/nrmicro884

Durvasula RV, Gumbs A, Panackal A, et al (1997) Prevention of insect-borne disease: an approach using transgenic symbiotic bacteria. Proc Natl Acad Sci USA 94:3274-3278. doi: 10.1073/pnas.94.7.3274

Figueras MJ, Beaz-Hidalgo R, Hossain MJ, Liles MR (2014) Taxonomic affiliation of new genomes should be verified using average nucleotide identity and multilocus phylogenetic analysis. Genome Announc. doi: 10.1128/genomeA.00927-14

Gascuel O (1997) BIONJ: an improved version of the NJ algorithm based on a simple model of sequence data. Mol Biol Evol 14:685-695. doi: 10.1093/oxfordjournals.molbev.a025808

Gavriel S, Jurkevitch E, Gazit Y, Yuval B (2011) Bacterially enriched diet improves sexual performance of sterile male Mediterranean fruit flies. J Appl Entomology 135:564-573. doi: 10.1111/j.1439-0418.2010.01605.x

Geer LY, Marchler-Bauer A, Geer RC, et al (2010) The NCBI BioSystems database. Nucleic Acids Res 38:D492-6. doi: 10.1093/nar/gkp858

Gould AL, Zhang V, Lamberti L, et al (2018) Microbiome interactions shape host fitness. Proc Natl Acad Sci USA 115:E11951-E11960. doi: 10.1073/pnas.1809349115

Hansen TB, Wiklund ED, Bramsen JB, et al (2011) miRNA-dependent gene silencing involving Ago2-mediated cleavage of a circular antisense RNA. EMBO J 30:4414-4422. doi: 10.1038/emboj.2011.359

Heine D, Holmes NA, Worsley SF, et al (2018) Chemical warfare between leafcutter ant symbionts and a co-evolved pathogen. Nat Commun 9:2208. doi: 10.1038/s41467-018-04520-1

Holmes NA, Innocent TM, Heine D, et al (2016) Genome analysis of two Pseudonocardia phylotypes associated with Acromyrmex leafcutter ants reveals their biosynthetic potential. Front Microbiol 7:2073. doi: 10.3389/fmicb.2016.02073

Hurst GDD, Frost CL (2015) Reproductive parasitism: maternally inherited symbionts in a biparental world. Cold Spring Harb Perspect Biol. doi: 10.1101/cshperspect.a017699

Husnik F, Nikoh N, Koga R, et al (2013) Horizontal gene transfer from diverse bacteria to an insect genome enables a tripartite nested mealybug symbiosis. Cell 153:1567-1578. doi: 10.1016/j.cell.2013.05.040

Hyatt D, Chen G-L, Locascio PF, et al (2010) Prodigal: prokaryotic gene recognition and translation initiation site identification. BMC Bioinformatics 11:119. doi: 10.1186/1471-210511-119

Jurkevitch E (2011) Riding the Trojan horse: combating pest insects with their own symbionts. Microb Biotechnol 4:620-627. doi: 10.1111/j.1751-7915.2011.00249.x

Kanehisa M, Sato Y, Kawashima M, et al (2016) KEGG as a reference resource for gene and protein annotation. Nucleic Acids Res 44:D457-62. doi: 10.1093/nar/gkv1070 
829

830

831

832

833

834

835

836

837

838

839

840

841

842

843

844

845

846

847

848

849

850

851

852

853

854

855

856

857

858

859

860

861

862

863

864

865

866

867

868

869

870

871

872

873

874

875

876

877

878

879

880

881

882

883

884

885

Kaneko T, Nakamura Y, Sato S, et al (2002) Complete genomic sequence of nitrogen-fixing symbiotic bacterium Bradyrhizobium japonicum USDA110 (supplement). DNA Res 9:225256. doi: 10.1093/dnares/9.6.225

Kim M, Oh H-S, Park S-C, Chun J (2014) Towards a taxonomic coherence between average nucleotide identity and 16S rRNA gene sequence similarity for species demarcation of prokaryotes. Int J Syst Evol Microbiol 64:346-351. doi: 10.1099/ijs.0.059774-0

Kitani S, Miyamoto KT, Takamatsu S, et al (2011) Avenolide, a Streptomyces hormone controlling antibiotic production in Streptomyces avermitilis. Proc Natl Acad Sci USA 108:1641016415. doi: $10.1073 /$ pnas. 1113908108

Konstantinidis KT, Tiedje JM (2005) Genomic insights that advance the species definition for prokaryotes. Proc Natl Acad Sci USA 102:2567-2572. doi: 10.1073/pnas.0409727102

Kovtunovych G, Lytvynenko T, Negrutska V, et al (2003) Identification of Klebsiella oxytoca using a specific PCR assay targeting the polygalacturonase pehX gene. Res Microbiol 154:587592. doi: 10.1016/S0923-2508(03)00148-7

Kuo C-H, Moran NA, Ochman H (2009) The consequences of genetic drift for bacterial genome complexity. Genome Res 19:1450-1454. doi: 10.1101/gr.091785.109

Lagesen K, Hallin P, Rødland EA, et al (2007) RNAmmer: consistent and rapid annotation of ribosomal RNA genes. Nucleic Acids Res 35:3100-3108. doi: 10.1093/nar/gkm160

Lauzon CR, McCombs SD, Potter SE, Peabody NC (2009) Establishment and vertical passage of Enterobacter (Pantoea) agglomerans and Klebsiella pneumoniae through all life stages of the Mediterranean fruit fly (Diptera: Tephritidae). Ann Entomol Soc Am 102:85-95.

Lawrence JG, Ochman H (1997) Amelioration of bacterial genomes: rates of change and exchange. J Mol Evol 44:383-397. doi: 10.1007/pl00006158

Lee C, Grasso C, Sharlow MF (2002) Multiple sequence alignment using partial order graphs. Bioinformatics 18:452-464. doi: 10.1093/bioinformatics/18.3.452

Leftwich PT (2012) Male reproductive success and population control in the Mediterranean fruit fly, Ceratitis capitata. Doctoral Thesis, University of East Anglia

Leftwich PT, Bolton M, Chapman T (2016) Evolutionary biology and genetic techniques for insect control. Evol Appl 9:212-230. doi: 10.1111/eva.12280

Leftwich PT, Clarke NVE, Hutchings MI, Chapman T (2018) Reply to Obadia et al.: Effect of methyl paraben on host-microbiota interactions in Drosophila melanogaster. Proc Natl Acad Sci USA 115:E4549-E4550. doi: 10.1073/pnas.1805499115

Leftwich PT, Edgington MP, Chapman T (2020) Transmission efficiency drives host-microbe associations. Proc Biol Sci 287:20200820. doi: 10.1098/rspb.2020.0820

Leftwich PT, Nash WJ, Friend LA, Chapman T (2017) Adaptation to divergent larval diets in the medfly, Ceratitis capitata. Evolution 71:289-303. doi: 10.1111/evo.13113

Lhocine N, Ribeiro PS, Buchon N, et al (2008) PIMS modulates immune tolerance by negatively regulating Drosophila innate immune signaling. Cell Host Microbe 4:147-158. doi: 10.1016/j.chom.2008.07.004

Lindberg BG, Tang X, Dantoft W, et al (2018) Nubbin isoform antagonism governs Drosophila intestinal immune homeostasis. PLoS Pathog 14:e1006936. doi: 10.1371/journal.ppat.1006936

Liu LJ, Martinez-Sañudo I, Mazzon L, et al (2016) Bacterial communities associated with invasive populations of Bactrocera dorsalis (Diptera: Tephritidae) in China. Bull Entomol Res 106:718-728. doi: 10.1017/S0007485316000390

Lobry JR (1996) Asymmetric substitution patterns in the two DNA strands of bacteria. Mol Biol Evol 13:660-665. doi: 10.1093/oxfordjournals.molbev.a025626

Lombard V, Bernard T, Rancurel C, et al (2010) A hierarchical classification of polysaccharide lyases for glycogenomics. Biochem J 432:437-444. doi: 10.1042/BJ20101185

Malacrinò A, Campolo O, Medina RF, Palmeri V (2018) Instar- and host-associated differentiation of bacterial communities in the Mediterranean fruit fly Ceratitis capitata. PLoS One 13:e0194131. doi: 10.1371/journal.pone.0194131

McCutcheon JP, Moran NA (2011) Extreme genome reduction in symbiotic bacteria. Nat Rev Microbiol 10:13-26. doi: 10.1038/nrmicro2670

McFall-Ngai M, Hadfield MG, Bosch TCG, et al (2013) Animals in a bacterial world, a new imperative for the life sciences. Proc Natl Acad Sci USA 110:3229-3236. doi: $10.1073 /$ pnas. 1218525110 
886

887

888

889

890

891

892

893

894

895

896

897

898

899

900

901

902

903

904

905

906

907

908

909

910

911

912

913

914

915

916

917

918

919

920

921

922

923

924

925

926

927

928

929

930

931

932

933

934

935

936

937

938

939

940

McMurdie PJ, Holmes S (2013) phyloseq: an R package for reproducible interactive analysis and graphics of microbiome census data. PLoS One 8:e61217. doi:

10.1371/journal.pone.0061217

Miller GL (1959) Use of dinitrosalicylic acid reagent for determination of reducing sugar. Anal Chem 31:426-428. doi: 10.1021/ac60147a030

Moran NA, Bennett GM (2014) The tiniest tiny genomes. Annu Rev Microbiol 68:195-215. doi: 10.1146/annurev-micro-091213-112901

Moran NA, McCutcheon JP, Nakabachi A (2008) Genomics and evolution of heritable bacterial symbionts. Annu Rev Genet 42:165-190. doi: 10.1146/annurev.genet.41.110306.130119

Moran NA, Tran P, Gerardo NM (2005) Symbiosis and insect diversification: an ancient symbiont of sap-feeding insects from the bacterial phylum Bacteroidetes. Appl Environ Microbiol 71:8802-8810. doi: 10.1128/AEM.71.12.8802-8810.2005

Moreno-Vivián C, Cabello P, Martínez-Luque M, et al (1999) Prokaryotic nitrate reduction: molecular properties and functional distinction among bacterial nitrate reductases. $\mathrm{J}$ Bacteriol 181:6573-6584. doi: 10.1128/JB.181.21.6573-6584.1999

Negri I, Franchini A, Gonella E, et al (2009) Unravelling the Wolbachia evolutionary role: the reprogramming of the host genomic imprinting. Proc Biol Sci 276:2485-2491. doi: $10.1098 / \mathrm{rspb} .2009 .0324$

Nelson WC, Howard MT, Sherman JA, Matson SW (1995) The traY gene product and integration host factor stimulate Escherichia coli DNA helicase l-catalyzed nicking at the $\mathrm{F}$ plasmid oriT. J Biol Chem 270:28374-28380.

Nikolouli K, Augustinos AA, Stathopoulou P, et al (2020) Genetic structure and symbiotic profile of worldwide natural populations of the Mediterranean fruit fly, Ceratitis capitata. BMC Genet 21:128. doi: 10.1186/s12863-020-00946-z

Nishida H (2012) Comparative analyses of base compositions, DNA sizes, and dinucleotide frequency profiles in archaeal and bacterial chromosomes and plasmids. Int J Evol Biol 2012:342482. doi: $10.1155 / 2012 / 342482$

Ochman H, Davalos LM (2006) The nature and dynamics of bacterial genomes. Science 311:1730-1733. doi: 10.1126/science.1119966

Ochman H, Lawrence JG, Groisman EA (2000) Lateral gene transfer and the nature of bacterial innovation. Nature 405:299-304. doi: 10.1038/35012500

Oksanen J, Kindt R, Legendre P, O'Hara B (2007) The vegan package. Community ecology ...

Oliver KM, Russell JA, Moran NA, Hunter MS (2003) Facultative bacterial symbionts in aphids confer resistance to parasitic wasps. Proc Natl Acad Sci USA 100:1803-1807. doi: 10.1073/pnas.0335320100

Overbeek R, Olson R, Pusch GD, et al (2014) The SEED and the Rapid Annotation of microbial genomes using Subsystems Technology (RAST). Nucleic Acids Res 42:D206-14. doi: 10.1093/nar/gkt1226

Parks DH, Imelfort M, Skennerton CT, et al (2015) CheckM: assessing the quality of microbial genomes recovered from isolates, single cells, and metagenomes. Genome Res 25:10431055. doi: 10.1101/gr.186072.114

Peplies J, Kottmann R, Ludwig W, Glöckner FO (2008) A standard operating procedure for phylogenetic inference (SOPPI) using (rRNA) marker genes. Syst Appl Microbiol 31:251257. doi: 10.1016/j.syapm.2008.08.003

Price MN, Dehal PS, Arkin AP (2010) FastTree 2 - approximately maximum-likelihood trees for large alignments. PLoS One 5:e9490. doi: 10.1371/journal.pone.0009490

Pruesse E, Peplies J, Glöckner FO (2012) SINA: accurate high-throughput multiple sequence alignment of ribosomal RNA genes. Bioinformatics 28:1823-1829. doi: 10.1093/bioinformatics/bts252

Quast C, Pruesse E, Yilmaz P, et al (2013) The SILVA ribosomal RNA gene database project: improved data processing and web-based tools. Nucleic Acids Res 41:D590-6. doi: $10.1093 /$ nar/gks1219

R Core Team (2019) R: A Language and Environment for Statistical Computing. R Foundation for Statistical Computing, Vienna, Austria

Rambaut A, Drummond AJ (2009) FigTree version 1.4.3. 
941

942

943

944

945

946

947

948

949

950

951

952

953

954

955

956

957

958

959

960

961

962

963

964

965

966

967

968

969

970

971

972

973

974

975

976

977

978

979

980

981

982

983

984

985

986

987

988

989

990

991

992

993

994

995

996

997

Reva ON, Tümmler B (2004) Global features of sequences of bacterial chromosomes, plasmids and phages revealed by analysis of oligonucleotide usage patterns. BMC Bioinformatics 5:90. doi: 10.1186/1471-2105-5-90

Richter M, Rosselló-Móra R (2009) Shifting the genomic gold standard for the prokaryotic species definition. Proc Natl Acad Sci USA 106:19126-19131. doi: 10.1073/pnas.0906412106

Rocha EPC, Danchin A (2002) Base composition bias might result from competition for metabolic resources. Trends Genet 18:291-294. doi: 10.1016/S0168-9525(02)02690-2

Sabree ZL, Huang CY, Okusu A, et al (2013) The nutrient supplying capabilities of Uzinura, an endosymbiont of armoured scale insects. Environ Microbiol 15:1988-1999. doi: 10.1111/1462-2920.12058

Saha R, Farrance CE, Verghese B, et al (2013) Klebsiella michiganensis sp. nov., a new bacterium isolated from a tooth brush holder. Curr Microbiol 66:72-78. doi: 10.1007/s00284-012-0245-x

Schloss PD, Westcott SL, Ryabin T, et al (2009) Introducing mothur: open-source, platformindependent, community-supported software for describing and comparing microbial communities. Appl Environ Microbiol 75:7537-7541. doi: 10.1128/AEM.01541-09

Shigenobu S, Watanabe H, Hattori M, et al (2000) Genome sequence of the endocellular bacterial symbiont of aphids Buchnera sp. APS. Nature 407:81-86. doi: 10.1038/35024074

Shin SH, Kim S, Kim JY, et al (2012) Complete genome sequence of Klebsiella oxytoca KCTC 1686, used in production of 2,3-butanediol. J Bacteriol 194:2371-2372. doi: 10.1128/JB.00026-12

Simão FA, Waterhouse RM, loannidis P, et al (2015) BUSCO: assessing genome assembly and annotation completeness with single-copy orthologs. Bioinformatics 31:3210-3212. doi: 10.1093/bioinformatics/btv351

Simmons JS (1926) A culture medium for differentiating organisms of typhoid-colon aerogenes groups and for isolation of certain fungi. J. Infect. Dis.

Sinotte VM, Freedman SN, Ugelvig LV, Seid MA (2018) Camponotus floridanus ants incur a tradeoff between phenotypic development and pathogen susceptibility from their mutualistic endosymbiont Blochmannia. Insects. doi: 10.3390/insects9020058

Sloan DB, Moran NA (2012) Endosymbiotic bacteria as a source of carotenoids in whiteflies. Biol Lett 8:986-989. doi: 10.1098/rsbl.2012.0664

Sohail M, Latif Z (2016) Phylogenetic analysis of polygalacturonase-producing Bacillus and Pseudomonas isolated from plant waste material. Jundishapur J Microbiol 9:e28594. doi: $10.5812 / \mathrm{jjm} .28594$

Stackebrandt E (2006) Taxonomic parameters revisited : tarnished gold standards. Microbiol Today 33:152-155.

Storelli G, Strigini M, Grenier T, et al (2018) Drosophila perpetuates nutritional mutualism by promoting the fitness of its intestinal symbiont Lactobacillus plantarum. Cell Metab 27:362377.e8. doi: 10.1016/j.cmet.2017.11.011

Takano E (2006) Gamma-butyrolactones: Streptomyces signalling molecules regulating antibiotic production and differentiation. Curr Opin Microbiol 9:287-294. doi: 10.1016/j.mib.2006.04.003

Tamas I, Klasson L, Canbäck B, et al (2002) 50 million years of genomic stasis in endosymbiotic bacteria. Science 296:2376-2379. doi: 10.1126/science.1071278

van Ham RCHJ, Kamerbeek J, Palacios C, et al (2003) Reductive genome evolution in Buchnera aphidicola. Proc Natl Acad Sci USA 100:581-586. doi: 10.1073/pnas.0235981100

Von Dohlen CD, Moran NA (2000) Molecular data support a rapid radiation of aphids in the Cretaceous and multiple origins of host alternation. Biological Journal of the Linnean Society 71:689-717. doi: 10.1006/bijl.2000.0470

Wegener CB (2002) Induction of defence responses against Erwinia soft rot by an endogenous pectate lyase in potatoes. Physiol Mol Plant Pathol 60:91-100. doi: 10.1006/pmpp.2002.0377

Weiss B, Kaltenpoth M (2016) Bacteriome-localized intracellular symbionts in pollen-feeding beetles of the genus Dasytes (Coleoptera, Dasytidae). Front Microbiol 7:1486. doi: 10.3389/fmicb.2016.01486

Whitten M, Dyson P (2017) Gene silencing in non-model insects: Overcoming hurdles using symbiotic bacteria for trauma-free sustainable delivery of RNA interference: Sustained RNA 

interference in insects mediated by symbiotic bacteria: Applications as a genetic tool and as a biocide. Bioessays. doi: 10.1002/bies.201600247

Whitten MMA, Facey PD, Del Sol R, et al (2016) Symbiont-mediated RNA interference in insects. Proc Biol Sci 283:20160042. doi: 10.1098/rspb.2016.0042

Wickham H (2017) Tidyverse: Easily Install and Load the' ' 'Tidyverse.

Wixon J (2001) Featured organism: reductive evolution in bacteria: Buchnera sp., Rickettsia prowazekii and Mycobacterium leprae. Comp Funct Genomics 2:44-48. doi: $10.1002 / \mathrm{cfg} .70$

Woruba DN, Morrow JL, Reynolds OL, et al (2019) Diet and irradiation effects on the bacterial community composition and structure in the gut of domesticated teneral and mature Queensland fruit fly, Bactrocera tryoni (Diptera: Tephritidae). BMC Microbiol 19:281. doi: 10.1186/s12866-019-1649-6

Wu D, Daugherty SC, Van Aken SE, et al (2006) Metabolic complementarity and genomics of the dual bacterial symbiosis of sharpshooters. PLoS Biol 4:e188. doi: 10.1371/journal.pbio.0040188

Xie F, Murray JD, Kim J, et al (2012) Legume pectate lyase required for root infection by rhizobia. Proc Natl Acad Sci USA 109:633-638. doi: 10.1073/pnas.1113992109

Yang Z (1994) Maximum likelihood phylogenetic estimation from DNA sequences with variable rates over sites: approximate methods. J Mol Evol 39:306-314. doi: 10.1007/BF00160154 